\title{
Hacerse adulto en España. Autoidentificación, creencias y autoestima de los hijos de inmigrantes*
}

\author{
Alejandro Portes \\ Erik Vickstrom \\ Universidad de Princeton \\ aportes@princeton.edu; evickstr@princeton.edu
}

Rosa Aparicio

Instituto Universitario Ortega y Gasset

rag.migraciones@fog.es

\section{Resumen}

Revisamos la literatura sobre los determinantes de las autoidentidades étnico-nacionales y de las autoestimas como preludio del examen de estos resultados en una amplia muestra estadísticamente representativa de adolescentes de segunda generación en Madrid y Barcelona. A pesar de que estos resultados psicosociales resultan maleables, siguen representando unas importantes dimensiones de la adaptación de los inmigrantes y pueden acarrear consecuencias significativas, tanto para la movilidad individual como para las movilidades colectivas. Las teorías actuales se basan en buena parte en información proveniente de los Estados Unidos y de otros países anglófonos. La disponibilidad de un nuevo y amplio estudio español nos permite comprobar esas teorías en un contexto sociocultural completamente diferente. El análisis concluye con un modelo de ecuaciones estructurales que resume los principales determinantes de las identidades y las autoestimas nacionales entre los hijos de inmigrantes en España. Se discuten las implicaciones teóricas y prácticas de estos hallazgos.

Palabras clave: autoidentidad; aculturación selectiva; aculturación disonante; inmigración; adolescentes.

* Artículo publicado en inglés en la British Journal of Sociology, 62 (3), 387-417 (2011). Traducción al castellano de Nerea Sanz.

Los datos en los que se basa este trabajo se recopilaron para el Estudio Longitudinal de la Segunda Generación (ILSEG), llevado a cabo mediante un consorcio ente la Universidad de Princeton y la Universidad Pontificia de Comillas, en Madrid, con el apoyo de la Fundación Spencer (Grant \#200800067). 
Abstract. Coming of Age in Spain: The Self-identification, Beliefs and Self-esteem of the Second Generation

We review the literature on determinants of ethnic/national self-identities and self-esteem as a prelude to examining these outcomes among a large, statistically representative sample of second generation adolescents in Madrid and Barcelona. While these psycho-social outcomes are malleable, they still represent important dimensions of immigrant adaptation and can have significant consequences both for individual mobility and collective mobilizations. Current theories are largely based on data from the USA and other Anglophone countries. The availability of a new large Spanish survey allows us to test those theories in an entirely different socio-cultural context. The analysis concludes with a structural equations model that summarizes key determinants of national identities and self-esteem among children of immigrants in Spain. Theoretical and practical implications of these findings are discussed.

Keywords: Self-identity; selective acculturation; dissonant acculturation; immigration; teenagers.

\begin{aligned} & \multicolumn{2}{c}{ Sumario } \\ & Repaso de la literatura e hipótesis Un modelo estructural de la adaptación \\ & Inmigración hacia España psicosocial \\ & Metodología Conclusión \\ & Hallazgos preliminares: resultados Referencias bibliográficas \\ & descriptivos Apéndice. Estadísticas descriptivas para \\ & Resultados multivariables variables utilizadas en el análisis \end{aligned}

Uno de los aspectos fundamentales del proceso de adaptación de los inmigrantes a una sociedad receptora es su cambio de identidades y las opiniones que llegan a tener sobre sus nuevos entornos. Si este es el caso en la primera generación de inmigrantes, ¿cuánto más lo será en su descendencia, en la segunda generación? Los inmigrantes adultos suelen tener sólidas identidades forjadas en sus países de origen y tienden a identificarse de forma muy limitada con el país que les recibe. Tal como dijo Glazer (1954), están en la sociedad pero no son todavía de ella. Por el contrario, sus hijos —incluidos aquéllos a los que trajeron del extranjero a una edad temprana - se crían en un nuevo ambiente, en el que la mayoría habrá de permanecer. Las formas en las que llegan a verse ellos mismos, así como sus actitudes positivas y negativas frente a la sociedad que es ahora la suya, pueden desempeñar un papel decisivo en su futuro, así como en sus posibilidades, de insertarse de manera satisfactoria en sus jerarquías de estatus y riqueza (Rumbaut, 2005; Portes y Hao, 1998).

Cada vez hay más literatura sobre las identidades étnicas y los niveles de autoestima de los jóvenes inmigrantes, tanto en los Estados Unidos como en la Europa occidental. En parte, este creciente interés se ha visto promovido por acontecimientos dramáticos, como las movilizaciones violentas en ciudades 
francesas en el otoño de 2005 — por muchos atribuidas a jóvenes de origen inmigrante- y la proliferación de bandas en Los Ángeles y otras ciudades estadounidenses - creadas también por adolescentes desafectos de segunda generación (Schneider, 2008; Vigil, 2002; Grascia, 2004). Menos espectaculares, aunque igualmente importantes a la larga, son las actitudes que esta creciente población de jóvenes ciudadanos llega a adoptar frente a su país receptor y a sus propias oportunidades de éxito en el mismo.

El presente artículo examina estas cuestiones en un nuevo país de inmigración -España- en base a una amplia muestra representativa de jóvenes de segunda generación en sus dos ciudades principales: Madrid y Barcelona. En los últimos años, se ha dado un notable crecimiento de la población extranjera en España que ha convertido al país en uno de los principales receptores, en términos absolutos y relativos, de la inmigración que se dirige a los países de la Europa occidental (Cachón, 2009; Pajares, 2009). La creciente población de niños inmigrantes e hijos de inmigrantes en España ofrece una clara oportunidad para comprobar las hipótesis existentes acerca de las identidades y la autoestima juveniles, desarrolladas fundamentalmente en base a la información proveniente de los Estados Unidos y otros países anglófonos. Revisamos la literatura de investigación existente y presentamos una breve visión general sobre la actual migración hacia España como preludio al análisis de este nuevo estudio.

\section{Repaso de la literatura e hipótesis}

En los últimos años, se ha conferido mucha importancia a las identidades étnicas y a la autoestima de los niños inmigrantes y de los hijos de inmigrantes. La literatura de investigación ha crecido a pasos agigantados, de modo que abarca a los grupos más diversos de extranjeros, desde mexicanos, dominicanos y chinos en los Estados Unidos (Jiménez, 2008; Macias, 2004; Louie, 2006), hasta caribeños en los Países Bajos (Van Niekerk, 2007), árabes en Francia (Keaton, 2006) y africanos subsaharianos en Italia (Andall, 2002). Este nivel de atención es digno de notarse, dado que la literatura también muestra que las autoetiquetas étnico-raciales pueden cambiar rápidamente según los tiempos y los contextos sociales (Portes y Rumbaut, 2001; Altschul et al., 2008; Bailey, 2000). Las autoidentidades y la autoestima son variables «blandas», sumamente maleables y flexibles. Sin embargo, dentro de contextos específicos, han aparecido asociadas a un gran número de importantes consecuencias, desde el éxito educacional y ocupacional hasta la militancia política (Diehl y Schnell, 2006; Feliciano, 2009; Portes y MacLeod, 1996).

Los hijos de inmigrantes se confrontan con una rivalidad entre dos culturas, idiomas y conjuntos de expectativas. Las consecuencias de esta confrontación no son uniformes y dependen de numerosos factores individuales, familiares y comunitarios. Como parte de su teoría de la asimilación segmentada, Portes y sus colaboradores propusieron una tipología tripartita de los resultados de la aculturación intergeneracional, la cual abarca: la aculturación consonante, 
en la que los inmigrantes y sus hijos aprenden y se adaptan a la nueva cultura y al nuevo idioma a un ritmo similar; la aculturación disonante, en la que la evolución cultural de los hijos se adelanta a la de sus padres, e incluso llegan eventualmente a rechazar el idioma y la cultura paternos frente a los de la nación receptora. Entre ambos extremos, hay un itinerario alternativo: el de la aculturación selectiva, en la que la adaptación al nuevo ambiente cultural se ve acompañada por la preservación del idioma de sus padres, así como de algunos elementos indispensables de su cultura (Portes y Zhou, 1992; Portes y Rumbaut, 2001).

En numerosas ocasiones, se han utilizado esta tipología y el modelo que la acompaña en ulteriores investigaciones como marco interpretativo de numerosos resultados empíricos relativos a las autoidentidades y a la autoestima de los adolescentes. Altschul et al. (2008) concluyeron, por ejemplo, que las «identidades puente», afines a los procesos de aculturación selectiva, resultaban de asociarse con resultados educacionales y ocupacionales superiores, al contrario que las estrechas identidades monoculturales, propias de los itinerarios disonantes. Bailey (2000) encontró que la preservación del idioma español constituía una herramienta fundamental para oponer resistencia a los estereotipos y a la discriminación raciales entre los dominicanos negros de segunda generación. Farver et al. (2002) expusieron cómo los jóvenes indios asiáticos de segunda generación tenían unos niveles de autoestima superiores y sufrían menos ansiedad cuando no existía una brecha cultural entre ellos y sus padres, una situación común a los que experimentaron una aculturación consonante o selectiva. En su estudio sobre los vietnamita-americanos en el Condado de Orange y Boston, San Juan (2005) halló que el mejor camino para «convertirse en estadounidense» era «seguir siendo vietnamita», una pauta que reflejaba la aculturación selectiva de la que también dieron cuenta Zhou y Bankston (1996) en su estudio sobre la comunidad vietnamita en Nueva Orleans.

Los determinantes de las identidades de los inmigrantes en la literatura de investigación incluyen el tiempo transcurrido en el país, la clase social y la educación, las actitudes de la población nativa y la continuidad o la interrupción de la migración del país de origen. Como era de esperar, el tiempo transcurrido en el país anfitrión y la presencia en él de generaciones anteriores incrementan la probabilidad de identificación con el nuevo entorno (Arriagada, 2007; Diehl y Schnell, 2006). Un cierto número de estudios ha encontrado también que la educación no incrementa la identificación con la sociedad anfitriona, sino que conduce a una visión más matizada y discriminadora que combina antiguas y nuevas identidades (Duncan y Trejo, n. d.; Feliciano, 2009; Hughes et al., 2006). El papel del estatus parental no está claro, pero resulta razonable asumir que una mayor educación y un mayor nivel ocupacional de los padres facilita la aculturación consonante o la selectiva, lo cual lleva a una mejor asimilación y a una mayor autoestima.

Existe consenso general en la literatura acerca de que la discriminación y los estereotipos raciales ralentizan el proceso de asimilación identitaria y amenazan la autoestima, lo cual estimula identidades reactivas y combativas. Los jóvenes 
de segunda generación que se ven sistemáticamente expuestos al mensaje de que, por razones raciales o culturales, no forman parte de la corriente social dominante, tienden a reafirmar las identidades étnicas que les marginan como medio para proteger su sentimiento de autoestima (Golash-Boza, 2006; Louie, 2006; Ono, 2002; Portes y Rumbaut, 2001, cap. 8). El trabajo de Jiménez (2008) también muestra que el reabastecimiento de la primera generación mediante la inmigración continua proveniente del país de origen agudiza las fronteras intergrupales y reafirma las identidades étnicas entre los mejicano-americanos, lo cual ralentiza la asimilación. Naturalmente, lo contrario ocurre con los descendientes de inmigrantes provenientes de países que han dejado de ser fuentes de inmigración por razones diversas (Lieberson, 1980; Perlmann, 2005).

La validez externa o representatividad de estas conclusiones varía enormemente. Numerosos estudios, especialmente aquéllos llevados a cabo entre grupos de inmigrantes en Europa, están fundamentados en pequeñas muestras de generabilidad limitada. Mientras que algunos estudios combinan el análisis de identidades étnico-raciales con las actitudes hacia la sociedad anfitriona, muchos otros no lo hacen, con lo cual dejan abierta la cuestión de la relación entre ambas variables. En cuanto a la asociación entre las autoidentidades, la autoestima y los planes de futuro, el consenso de la literatura de investigación se opone a posiciones convencionales que relacionan la total aculturación y la asimilación identificacional con unos niveles de ambición más elevados. Los trabajos de Zarate et al. (2005), Waters (1996), Bailey (2000, 2001), Altschul et al. (2008) y otros apuntan a una aculturación selectiva, junto con una fuerte conservación del idioma de los padres y unas buenas relaciones intergeneracionales, como conductores hacia unos resultados de adaptación positivos en cuanto a las aspiraciones y a la autoestima.

Nosotros nos hemos centrado, por nuestra parte, en las autoidentidades, las actitudes hacia la sociedad anfitriona y los niveles de autoestima de los jóvenes de origen inmigrante en España. Nos ocupamos de las dos primeras variables conjuntamente para, después, analizar la autoestima y sus determinantes. Del repaso de la literatura de investigación hasta aquí ofrecido, extraemos una serie de determinantes que se pueden clasificar en factores objetivos y subjetivos. La relación causal entre los determinantes objetivos y los tres resultados sociopsicológicos de interés resulta bastante clara, mientras que los determinantes que implican características subjetivas se han de considerar más bien correlacionales que causales. Entre los factores objetivos, se incluyen la edad, el sexo, el lugar de nacimiento, el tiempo de residencia en el país, el lugar de nacimiento del padre y de la madre, el estatus familiar y el conocimiento del idioma del país anfitrión. Además, incluyen la nacionalidad de origen en la medida en que puede afectar a las autoidentidades como distinta del lugar de nacimiento. Los factores subjetivos incluyen las experiencias de discriminación y las relaciones con los progenitores, indicativas de una aculturación consonante y selectiva o disonante.

La literatura de investigación que identifica a estos determinantes no resulta siempre del todo clara en cuanto a la dirección de los procesos causales. 
Sin embargo, basándonos en resultados anteriores, podemos avanzar una serie limitada de hipótesis:

- El lugar de nacimiento (nativo vs. nacido en el extranjero) influye significativamente en las autoidentidades de los jóvenes de origen inmigrante, puesto que los nativos tienen más posibilidades de identificarse con la sociedad anfitriona.

- El tiempo de residencia conduce también hacia una mayor identificación y una orientación más positiva hacia la sociedad anfitriona.

- Los jóvenes de origen mixto, uno de cuyos padres ha nacido en el país anfitrión, se sienten mejor identificados con éste y muestran una orientación más positiva hacia él que aquéllos cuyos dos padres son de origen extranjero.

- El conocimiento del idioma del país anfitrión incrementa también la identificación con el mismo, así como la autoestima.

- El estatus socioeconómico familiar debería conducirles en la misma dirección, en la medida en que facilita un proceso de aculturación más fluido.

- Repetidas experiencias de discriminación disminuyen la autoestima y pueden ralentizar la identificación con la sociedad anfitriona, lo cual lleva al desarrollo de actitudes más críticas hacia la misma.

- De forma similar, los hijos provenientes de grupos inmigrantes racializados tienden a desarrollar identidades reactivas. Se niegan a identificarse con la sociedad dominante.

- Unas relaciones intergeneracionales (entre padres e hijos) positivas, indicativas de una aculturación consonante y selectiva, aumentan la autoestima. Las relaciones negativas indicativas de una aculturación disonante producen el efecto contrario.

Otras relaciones son ambiguas. Por ejemplo: no resultan claros los efectos que la edad y el sexo tienen en estos resultados psicosociales, de qué forma influyen en ellos los orígenes nacionales específicos o cómo la autoidentidad se relaciona con la autoestima. Tampoco está claro cómo las relaciones intergeneracionales afectan a las autoidentidades y a las actitudes hacia la sociedad anfitriona. Estos interrogantes se hacen más evidentes en un nuevo contexto de recepción en el que la presencia de inmigrantes y su prole es un fenómeno relativamente nuevo. A continuación, describimos este contexto, seguido de la metodología utilizada para examinar estas hipótesis.

\section{Inmigración hacia España}

Tradicionalmente, España ha sido un país de emigración. Ha enviado millones de trabajadores emigrantes, primero, a Latinoamérica y, tras la Segunda Guerra Mundial, al norte de Europa. Desde que se unió al Mercado Común Europeo y, consiguientemente, a la Unión Europea, el país experimentó un continuo proceso de crecimiento económico que le llevó a ser incluido entre los países desarrollados. A raíz de esto, la emigración de trabajadores no sólo 
cesó, sino que también se invirtió para dar paso a la vuelta de millones de antiguos emigrantes (Cachón, 2009; Calavita, 2005). Desde principios de la década de 1990, España se ha visto en el papel de receptor de flujos migratorios, provenientes, en un principio, del cercano Marruecos y, ulteriormente, de países latinoamericanos, Europa del Este e incluso de Asia (Carvajal Gómez, 2006). Por consiguiente, la población extranjera creció de manera exponencial y, en 2008, alcanzó los 5,6 millones, cerca del 12\% del total de la población (Observatorio Permanente de la Inmigración, 2009; Cachón, 2009). La cifra es similar a la de la proporción de la población estadounidense nacida en el extranjero $(12,5 \%)$, a pesar de que el periodo de recepción de inmigrantes en España ha sido mucho más corto — apenas veinte años.

Inevitablemente, la primera generación de inmigrantes engendró una segunda generación que actualmente representa la parte integrante de la población que más rápidamente aumenta, la de 18 años y menos (Aparicio, 2006). $\mathrm{Al}$ no ser tradicionalmente un país de inmigración, España no estaba preparada para guiar en su incorporación a sus nuevos inmigrantes, y menos aún a su prole. La llegada de esta joven población a las escuelas y a las calles se vio acompañada de mucha incertidumbre y bastante ansiedad entre los españoles acerca de lo que este fenómeno podía augurar para su nación (Pajares, 2009; Aparicio y Tornos, 2008). Los artículos periodísticos sobre el crecimiento de bandas juveniles latinas o el peligro del fundamentalismo islámico entre los jóvenes marroquíes y otros musulmanes de segunda generación han proliferado, mientras que el Gobierno español y los de las comunidades autónomas han desarrollado numerosas políticas a favor de la integración de los hijos de inmigrantes en las escuelas y para evitar los tempranos pero preocupantes signos de asimilación descendente (Sotelo, 2005; Díez Nicolás, 2006).

Sin embargo, hasta el momento, han sido pocos los estudios empíricos sobre hijos de inmigrantes en España que se han llevado a cabo, y los que existen se basan en muestras no representativas o exclusivamente locales (Aparicio, 2006; Aparicio y Tornos, 2008; Gualda, 2009). Por lo general, todavía es una población joven en la que la mayoría de los integrantes siguen siendo niños o adolescentes. Sin embargo, es en la adolescencia temprana cuando las autoidentidades y las actitudes frente a la sociedad anfitriona comienzan a tomar forma. Una preocupación clave es qué dirección tomarán y de qué modo variarán dependiendo del origen nacional, el tiempo de residencia en el país y otros factores. En el pasado, se demostró que el sentido de la identificación o del distanciamiento de la sociedad anfitriona es un importante factor asociado a los planes trazados por los jóvenes para su futuro y a sus diferentes caminos de adaptación (Feliciano y Rumbaut, 2005; Zhou et al., 2008; Portes y MacLeod, 1996).

En consecuencia, el estudio de las imágenes de sí mismos, las actitudes frente a la sociedad anfitriona y la autoestima de la segunda generación en España ofrece una oportunidad de arrojar luz sobre una población desconocida hasta el momento, con lo cual se comprueba al mismo tiempo las teorías existentes en un nuevo contexto social. Como se ha visto con anterioridad, las pro- 
puestas teóricas sobre los orígenes de las autoidentidades y autoestimas de los adolescentes, sus causas y correlatos derivan principalmente de investigaciones empíricas estadounidenses, con contribuciones limitadas provenientes de otros países angloparlantes. El hecho de aplicarlas en un contexto social y cultural completamente diferente nos brinda la oportunidad de probar la aplicabilidad de estas teorías en otros lugares, así como de ampliarlas y perfeccionarlas.

\section{Metodología}

La información en la que se basan los siguientes análisis son el producto de un esfuerzo colaborativo entre centros de investigación con sede en universidades de los Estados Unidos y España, con el objetivo de entrevistar a muestras representativas de jóvenes de segunda generación en sus principales áreas de concentración. Con este fin, los investigadores buscaron la aprobación y el apoyo de las autoridades educativas de Madrid y Barcelona - las dos ciudades con mayor índice de recepción de inmigrantes en España (Observatorio Permanente de la Inmigración, 2009). Cuando los obtuvieron, el equipo de investigación procedió a establecer muestras aleatorias de escuelas de educación secundaria en cada una de las dos áreas metropolitanas, estratificándolas por tipo de escuela (pública o privada) y por la ubicación geográfica. Con este fin, las respectivas autoridades educativas de las comunidades autónomas pusieron a disposición de los investigadores listas completas de los centros educativos. El diseño de la muestra aleatoria estratificada consiguió mantener una fracción de muestreo constante por tipo de escuela y región dentro de cada área metropolitana, lo cual hizo, por consiguiente, que la muestra fuera estadísticamente representativa de los universos estudiantiles respectivos (Kish, 1967; Firebaugh, 2008).

Dentro de cada centro escolar, se incluyeron todos los estudiantes que reunían los requisitos necesarios. Se definió la «segunda generación» como aquellos adolescentes con al menos un padre nacido en el extranjero, que hubieran nacido en España o hubieran sido traídos al país antes de los 12 años. De forma convencional, aquéllos nacidos en el país anfitrión se definen como «auténtica» segunda generación, mientras que a aquéllos que han sido traídos del extranjero a una edad temprana se les define como "generación 1,5» (Rumbaut, 2004). La mayoría de los jóvenes inmigrantes en España acuden a colegios públicos, pero una importante minoría se ha hecho un hueco en los colegios concertados, la mayoría vinculados a la Iglesia católica ${ }^{1}$. Una de las cuestiones principales para el análisis es si las autoidentidades y las actitudes frente a España de estos adolescentes varían dependiendo del tipo de escuela al que acuden. Desde una

1. Las escuelas privadas de esta muestra son las concertadas, puesto que cuentan con subvenciones del Gobierno y la mayoría deben seguir las directrices educacionales estatales. La gran mayoría de estas escuelas están afiliadas a la Iglesia católica. Se excluyó un pequeño grupo de escuelas privadas no concertadas, puesto que son instituciones con matrículas muy caras a las que asisten muy pocos hijos de inmigrantes. 
Tabla 1. Características demográficas de la segunda generación en España (2008)

\begin{tabular}{|c|c|c|c|c|}
\hline Variables & Valores & Barcelona & Madrid & Totales \\
\hline \multirow[t]{2}{*}{ Sexo } & Porcentaje masculino & 54,13 & 48,54 & 51,38 \\
\hline & Porcentaje femenino & 45,87 & 51,46 & 48,62 \\
\hline \multirow[t]{2}{*}{ Edad } & Media & 13,48 & 14,36 & 13,91 \\
\hline & Mediana & 13 & 14 & 14 \\
\hline \multirow[t]{2}{*}{ País de nacimiento } & Porcentaje correspondiente a España & 15,94 & 13,56 & 14,77 \\
\hline & Porcentaje correspondiente al extranjero & 84,06 & 86,44 & 85,23 \\
\hline \multirow{2}{*}{$\begin{array}{l}\text { Años de residencia en España } \\
\text { (para aquéllos nacidos en el } \\
\text { extranjero) }\end{array}$} & Media & 4,82 & 5,76 & 5,26 \\
\hline & Mediana & 5 & 6 & 5 \\
\hline \multirow[t]{2}{*}{ Composición familiar } & Porcentaje de los que viven con los padres naturales & 65,80 & 66,87 & 66,32 \\
\hline & Porcentajes de otras disposiciones & 34,20 & 33,13 & 33,68 \\
\hline \multirow[t]{3}{*}{ Curso de ESO } & $1 .^{\circ}$ & 33,59 & 8,77 & 21,67 \\
\hline & $2 .^{\circ}$ & 34,73 & 54,40 & 44,18 \\
\hline & $3 .^{\circ}$ & 31,68 & 36,83 & 34,15 \\
\hline \multirow[t]{2}{*}{ País de nacimiento del padre } & Porcentaje correspondiente a España & 5,52 & 5,36 & 5,44 \\
\hline & Porcentaje correspondiente a países extranjeros & 94,48 & 94,64 & 94,56 \\
\hline \multirow{2}{*}{$\begin{array}{l}\text { País de nacimiento } \\
\text { de la madre }\end{array}$} & Porcentaje correspondiente a España & 4,70 & 3,87 & 4,29 \\
\hline & Porcentaje correspondiente a países extranjeros & 95,30 & 96,13 & 95,71 \\
\hline \multicolumn{5}{|l|}{$\begin{array}{l}\text { Conocimiento del español } \\
\text { (en tantos por ciento) }\end{array}$} \\
\hline \multirow[t]{4}{*}{ Lo habla } & Poco & 3,69 & 1,05 & 2,39 \\
\hline & Algo & 5,68 & 3,45 & 4,58 \\
\hline & Bien & 23,86 & 22,95 & 23,42 \\
\hline & Perfectamente & 66,77 & 72,55 & 69,61 \\
\hline \multirow[t]{4}{*}{ Lo comprende } & Poco & 3,03 & 0,78 & 1,93 \\
\hline & Algo & 3,50 & 2,37 & 2,95 \\
\hline & Bien & 18,09 & 19,46 & 18,76 \\
\hline & Perfectamente & 75,38 & 77,39 & 76,36 \\
\hline
\end{tabular}

Fuente: Investigación Longitudinal de la Segunda Generación (ILSEG), 2008.

perspectiva geográfica, la muestra también se estratificó por zonas para asegurar que se incluían todos los centros escolares de cada área metropolitana. Dada la gran concentración de escuelas en las respectivas ciudades principales, una simple muestra aleatoria hubiera excluido a muchas de las que se encuentran en las zonas de las afueras. En el estudio, tomaron parte un total de 180 centros escolares, 101 en Madrid y 79 en Barcelona, de los que 111 eran públicos y el resto, privados.

La educación secundaria básica en España es obligatoria y sus estudiantes se encuentran, en su inmensa mayoría, en los años de la adolescencia temprana. Estas dos características resultan metodológicamente convenientes, pues garantizan que una muestra de las escuelas será representativa de su cohorte de edad respectiva, puesto que casi todos sus miembros siguen en la escuela. Las importantes bajas académicas en los subsiguientes años reduce la superposición entre la población estudiantil y su cohorte de edad respectiva. El estudio se centró 
en los primeros tres años de educación secundaria obligatoria $(\mathrm{ESO})^{2}$, porque son los que incluyen a la población con una media de edad de 13-14 años, que representa el universo de interés. A esta edad, casi todos los niños están matriculados en la escuela y son suficientemente maduros como para poder cumplimentar un cuestionario simple. Personal del proyecto se encontraba cerca para facilitar el proceso, a fin de clarificar dudas y de ayudar a los estudiantes a responder preguntas durante las sesiones en las que se administraban los cuestionarios en cada uno de los centros escolares escogidos. El tamaño de la muestra llegó a los 6.905: 3.375 en Madrid y 3.530 en Barcelona. Con una fracción de muestreo constante, la muestra resulta autoponderada con respecto al universo total y a cada uno de los estratos muestreados. La tabla 1 presenta sus características demográficas básicas desglosadas por áreas metropolitanas.

\section{Hallazgos preliminares: resultados descriptivos}

La tabla 2 muestra la distribución de frecuencias en ambas ciudades de las autoidentificaciones nacionales y de las variables actitudinales relacionadas con las mismas. Como se ha señalado anteriormente, en un primer momento, tratamos de esas variables para, más adelante, analizar la autoestima y sus determinantes. Una primera e importante conclusión es que la autoidentificación como «españoles» solo engloba a un tercio de la muestra total, mientras que el resto se identifica fundamentalmente con el país de nacimiento de sus padres. Esta pauta se repite entre los jóvenes de Madrid y Barcelona. En ambas ciudades, una gran mayoría consideraba sus autoidentidades como «importantes» o «muy importantes», un resultado que añade peso a estas conclusiones. En esencia, muestran que dos tercios de los jóvenes de segunda generación que viven en España y se están educando en este país aún forman más parte de la sociedad de origen de sus padres que de la sociedad española.

Estos resultados se ven respaldados por los de la siguiente fila de la tabla 2, que muestran un hecho todavía más sorprendente: al contrario de lo que ocurre en otros países de inmigración, una gran mayoría de los hijos de inmigrantes en España tiene pensado vivir en otro lugar cuando se hagan adultos. Tan solo un cuarto tiene la intención de permanecer en España, casi la misma proporción de los que tienen pensado irse a vivir a Norteamérica. Un 17\% adicional tiene planeado mudarse a otro país de Europa occidental. Esta falta de apego para con la sociedad receptora resulta notoria y precisa de análisis adicionales. De forma preliminar, los resultados indican que, habiendo llegado o nacido en España, la mayoría de los hijos de inmigrantes no consideran al país como su último destino, sino como un peldaño o una plataforma en su camino hacia otra parte.

El conjunto de respuestas actitudinales presentadas a continuación, en la tabla 2, concuerda con estas conclusiones. Del lado positivo, una gran mayoría de los encuestados dijo que, en cuanto a las oportunidades de ascenso, en España no existe discriminación racial. La percepción generalizada es que el país es

2. Enseñanza secundaria obligatoria (ESO). 
Tabla 2. Autoidentidades y actitudes relacionadas de los jóvenes de la segunda generación de Madrid y Barcelona (2008)

\begin{tabular}{|c|c|c|c|c|c|c|c|}
\hline \multirow{2}{*}{ Variables } & \multirow[b]{2}{*}{ Valores } & \multicolumn{2}{|c|}{ Madrid } & \multicolumn{2}{|c|}{ Barcelona } & \multicolumn{2}{|c|}{ Totales } \\
\hline & & $\%$ & $\mathrm{~N}$ & $\%$ & $\mathrm{~N}$ & $\%$ & $\mathrm{~N}$ \\
\hline \multirow[t]{3}{*}{ «¿Se considera español?» } & Sí & 27,0 & 911 & 30,3 & 1.069 & 28,7 & 1.980 \\
\hline & No & 68,4 & 2.308 & 63,6 & 2.246 & 66,0 & 4.554 \\
\hline & Ninguna/NC ${ }^{1}$ & 4,6 & 156 & 6,1 & 215 & 5,4 & 371 \\
\hline \multirow{7}{*}{$\begin{array}{l}\text { «Si no es así, ¿cuál considera } \\
\text { que es su nacionalidad?»² }\end{array}$} & Boliviana & 6,1 & 136 & - & - & 5,1 & 231 \\
\hline & Colombiana & 7,2 & 161 & 10,6 & 245 & 8,9 & 406 \\
\hline & Dominicana & - & - & 5,6 & 128 & 6,1 & 276 \\
\hline & Ecuatoriana & 24,9 & 560 & 33,2 & 765 & 29,1 & 1,325 \\
\hline & Marroquí & 7,5 & 168 & 5,6 & 130 & 6,5 & 298 \\
\hline & Peruana & 6,1 & 136 & 6,1 & 141 & 6,1 & 277 \\
\hline & Rumana & - & - & 8,3 & 192 & - & - \\
\hline \multirow{4}{*}{$\begin{array}{l}\text { «¿Cuánta importancia } \\
\text { le confiere usted a su } \\
\text { nacionalidad?»? }\end{array}$} & Muy importante & 55,8 & 1.882 & 54,7 & 1.931 & 55,2 & 3.813 \\
\hline & Importante & 29,4 & 992 & 29,1 & 1.028 & 29,3 & 2.020 \\
\hline & Sin importancia & 11,9 & 402 & 9,2 & 326 & 10,5 & 728 \\
\hline & $\mathrm{NS}^{3} / \mathrm{NC}$ & 2,9 & 99 & 6,9 & 245 & 5,0 & 344 \\
\hline \multirow{7}{*}{$\begin{array}{l}\text { «En qué país le gustaría } \\
\text { vivir cuando sea adulto?» }\end{array}$} & España & 25,9 & 874 & 22,1 & 781 & 24,0 & 1.655 \\
\hline & País de Europa occidental & 15,2 & 513 & 16,4 & 579 & 15,8 & 1.092 \\
\hline & País norteamericano & 23,6 & 798 & 24,1 & 852 & 23,9 & 1.650 \\
\hline & País sudamericano & 13,3 & 449 & 12,8 & 451 & 13,0 & 900 \\
\hline & País caribeño & 3,1 & 106 & 1,9 & 68 & 2,5 & 174 \\
\hline & Otros & 13,9 & 470 & 12,8 & 452 & 13,4 & 922 \\
\hline & NS/NC & 4,9 & 165 & 9,8 & 347 & 7,4 & 512 \\
\hline \multirow{5}{*}{$\begin{array}{l}\text { «No todo el mundo goza de } \\
\text { las mismas oportunidades } \\
\text { económicas en España» }\end{array}$} & Muy de acuerdo & 19,9 & 673 & 19,0 & 672 & 19,5 & 1.345 \\
\hline & De acuerdo & 38,0 & 1.281 & 33,9 & 1.197 & 35,9 & 2.478 \\
\hline & En desacuerdo & 25,4 & 858 & 20,4 & 719 & 22,8 & 1.577 \\
\hline & Muy en desacuerdo & 8,9 & 300 & 10,3 & 364 & 9,6 & 664 \\
\hline & NS & 7,8 & 263 & 16,4 & 578 & 12,2 & 841 \\
\hline \multirow{5}{*}{$\begin{array}{l}\text { «La vida en España debilita } \\
\text { las relaciones familiares» }\end{array}$} & Muy de acuerdo & 10,5 & 356 & 10,3 & 365 & 10,4 & 721 \\
\hline & De acuerdo & 25,8 & 872 & 24,1 & 850 & 24,9 & 1.722 \\
\hline & En desacuerdo & 39,5 & 1.334 & 33,5 & 1.182 & 36,4 & 2.516 \\
\hline & Muy en desacuerdo & 17,2 & 582 & 16,7 & 591 & 17,0 & 1.173 \\
\hline & NS & 6,8 & 231 & 15,4 & 542 & 11,2 & 773 \\
\hline \multirow{5}{*}{$\begin{array}{l}\text { «No hay un mejor país para } \\
\text { vivir que España» }\end{array}$} & Muy de acuerdo & 6,9 & 232 & 7,3 & 257 & 7,1 & 489 \\
\hline & De acuerdo & 15,2 & 512 & 15,0 & 531 & 15,1 & 1.043 \\
\hline & En desacuerdo & 43,1 & 1.455 & 37,1 & 1.311 & 40,1 & 2.766 \\
\hline & Muy en desacuerdo & 28,7 & 967 & 26,7 & 941 & 27,6 & 2.908 \\
\hline & NS & 6,2 & 209 & 13,9 & 490 & 10,1 & 699 \\
\hline \multirow{5}{*}{$\begin{array}{l}\text { «En España, la gente de } \\
\text { color goza de las mismas } \\
\text { oportunidades para avanzar } \\
\text { que los blancos» }\end{array}$} & Muy de acuerdo & 51,3 & 1.732 & 39,1 & 1.381 & 45,1 & 3.113 \\
\hline & De acuerdo & 23,4 & 789 & 26,1 & 921 & 24,8 & 1.710 \\
\hline & En desacuerdo & 12,5 & 421 & 13,9 & 490 & 13,2 & 911 \\
\hline & Muy en desacuerdo & 6,8 & 231 & 7,2 & 253 & 7,0 & 484 \\
\hline & NS & 6,0 & 202 & 13,7 & 485 & 9,9 & 687 \\
\hline \multirow{5}{*}{$\begin{array}{l}\text { «Por lo general, los españoles } \\
\text { se sienten superiores a los } \\
\text { extranjeros» }\end{array}$} & Muy de acuerdo & 31,1 & 1.049 & 26,8 & 945 & 28,9 & 1.994 \\
\hline & De acuerdo & 35,2 & 1.188 & 31,0 & 1.096 & 33,1 & 2.284 \\
\hline & En desacuerdo & 20,7 & 698 & 20,2 & 712 & 20,4 & 1.410 \\
\hline & Muy en desacuerdo & 6,6 & 224 & 8,4 & 296 & 7,5 & 520 \\
\hline & NS & 6,4 & 216 & 13,6 & 481 & 10,1 & 697 \\
\hline
\end{tabular}

1. NC: no contesta.

2. Las nacionalidades consideradas son aquéllas que representan al menos el $5 \%$ de las muestras de las ciudades y del total. 3. NS: no sabe.

Fuente: Investigación Longitudinal de la Segunda Generación (ILSEG), 2008. 
igualitario, pero que no resulta particularmente atractivo en cuanto a oportunidades se refiere. Por consiguiente, sólo un cuarto de los encuestados está parcial o totalmente de acuerdo con la siguiente afirmación: «No hay mejor país para vivir que España». Relativizando la impresión de igualitarismo transmitida por el ítem sobre oportunidades económicas, una proporción similar (69\%) piensa que «los españoles se consideran superiores a los extranjeros». Las diferencias entre Madrid y Barcelona en este aspecto, al igual que en los anteriores, son secundarias, lo que nos indica que, en lo referente a identidades y opiniones, no hay diferencias importantes entre las dos principales áreas de asentamiento de los inmigrantes en España.

La tabla 3 muestra las distribuciones de frecuencia desglosadas por tipos de centros escolares y lugares de nacimiento. Contrariamente a lo que se podría esperar, no existen diferencias significativas en cuanto a las autoidentidades, a los planes de vida futuros o hacia las actitudes respecto al país según el tipo de escuela. Las dos submuestras presentan fundamentalmente el mismo perfil. La cuestión cambia cuando las variables se tabulan por lugar de nacimiento. La auténtica segunda generación — la minoría nacida en España- muestra niveles muy superiores de autoidentificación con el país, actitudes considerablemente más positivas hacia el mismo y planes mucho más firmes de vivir en él cuando sean adultos. Este resultado es precisamente el que la literatura de investigación nos llevaría a esperar, pues sugiere que gran parte de la débil vinculación de los jóvenes inmigrantes con España proviene del poco tiempo que llevan en el pais. Los niños nacidos en el extranjero y con tan solo unos años de experiencia en el país no han tenido tiempo, como grupo, de cambiar su lealtad y sus percepciones. Sus identidades no españolas no son tan indicadoras de una postura de oposición como de una aculturación incompleta. Simultáneamente, los resultados muestran también que no todos los jóvenes nacidos en España se identifican con el país, tienen una buena opinión del mismo o tienen pensado quedarse. Estas diferencias tocan directamente a la cuestión de las identidades reactivas o opositoras que se consideran a continuación.

Las figuras 1 y 2 presentan histogramas que representan las autoidentidades nacionales y los planes de futuro de todas las nacionalidades que, en la muestra, cuentan al menos con cien casos, de los que al menos quince nacieron en el país $^{3}$. El panorama general es el mismo. Consistentemente, la autoidentificación con España es muy superior en la auténtica segunda generación independientemente de la nacionalidad. Amplias mayorías de los nacidos en el país se autodefinen como «españoles», salvo por la única excepción de la segunda generación de dominicanos, cuyas autoidentificaciones nacionales se dividen aproximadamente por igual.

3. Los orígenes nacionales fueron asignados a los extranjeros de acuerdo con su país de nacimiento y, a los que nacieron en España, de acuerdo con el país de nacimiento de sus padres. Si los padres nacieron en diferentes países, se les asignó la nacionalidad del padre si éste estaba presente en el hogar y, en el caso contrario, se les asignó la nacionalidad de la madre. Si uno de los padres nació en España, se asignó la nacionalidad del padre extranjero. 
Tabla 3. Autoidentidades y actitudes relativas a ellas según tipo de escuela y país de nacimiento (España, 2008)

\begin{tabular}{|c|c|c|c|c|c|}
\hline \multirow[b]{2}{*}{ Variable } & \multirow[b]{2}{*}{ Valores } & \multicolumn{2}{|c|}{ Tipo de escuela ${ }^{1}$} & \multicolumn{2}{|c|}{ País de nacimiento ${ }^{1}$} \\
\hline & & Pública & Privada & España & Extranjero \\
\hline \multirow[t]{3}{*}{ «¿Se considera español?» } & Sí & 30,40 & 30,20 & 77,67 & 22,08 \\
\hline & No & 69,80 & 69,70 & 22,31 & 77,92 \\
\hline & & \multicolumn{2}{|c|}{$\left(\chi^{2}=0,03 \text { n. s. }\right)^{2}$} & \multicolumn{2}{|c|}{$\left(\chi^{2}=120,0 p<0,000\right)$} \\
\hline «¿Cuánta importancia & Importante o muy importante & 88,02 & 89,91 & 82,19 & 90,09 \\
\hline \multirow{2}{*}{$\begin{array}{l}\text { le confiere usted a su } \\
\text { nacionalidad?» }\end{array}$} & Sin importancia. Otro & 11,98 & 10,09 & 17,81 & 9,91 \\
\hline & & \multicolumn{2}{|c|}{$\left(\chi^{2}=5,91\right.$ n. s. $)$} & \multicolumn{2}{|c|}{$\left(\chi^{2}=51,76 p<0,000\right)$} \\
\hline \multirow{3}{*}{$\begin{array}{l}\text { ¿En qué país le gustaría } \\
\text { vivir cuando sea adulto?» }\end{array}$} & España & 26,55 & 25,14 & 40,32 & 23,60 \\
\hline & Otros & 73,45 & 74,86 & 59,68 & 76,40 \\
\hline & & \multicolumn{2}{|c|}{$\left(\chi^{2}=1,63\right.$ n.s. $)$} & \multicolumn{2}{|c|}{$\left(\chi^{2}=115,59 p<0,000\right)$} \\
\hline «No hay un mejor país para & De acuerdo. Muy de acuerdo & 24,02 & 25,46 & 30,73 & 23,57 \\
\hline \multirow[t]{2}{*}{ vivir que España» } & En desacuerdo. Otro & 75,98 & 74,54 & 69,27 & 76,43 \\
\hline & & \multicolumn{2}{|c|}{$\left(\chi^{2}=1,73\right.$ n. s. $)$} & \multicolumn{2}{|c|}{$\left(\chi^{2}=21,81 p<0,000\right)$} \\
\hline \multirow{3}{*}{$\begin{array}{l}\text { «Por lo general, los españoles } \\
\text { se sienten superiores a los } \\
\text { extranjeros» }\end{array}$} & De acuerdo. Muy de acuerdo & 70,24 & 67,36 & 63,18 & 69,93 \\
\hline & En desacuerdo. Otro & 29,76 & 32,64 & 36,82 & 30,07 \\
\hline & & \multicolumn{2}{|c|}{$\left(\chi^{2}=5,95\right.$ n. s. $)$} & \multicolumn{2}{|c|}{$\left(\chi^{2}=16,91 p<0,000\right)$} \\
\hline
\end{tabular}

1. Valores en tanto por ciento.

Fuente: Investigación Longitudinal de la Segunda Generación (ILSEG), 2008.

Figura 1. Autoidentificación por lugares de nacimietno para diferentes nacionalidades en España (2008)

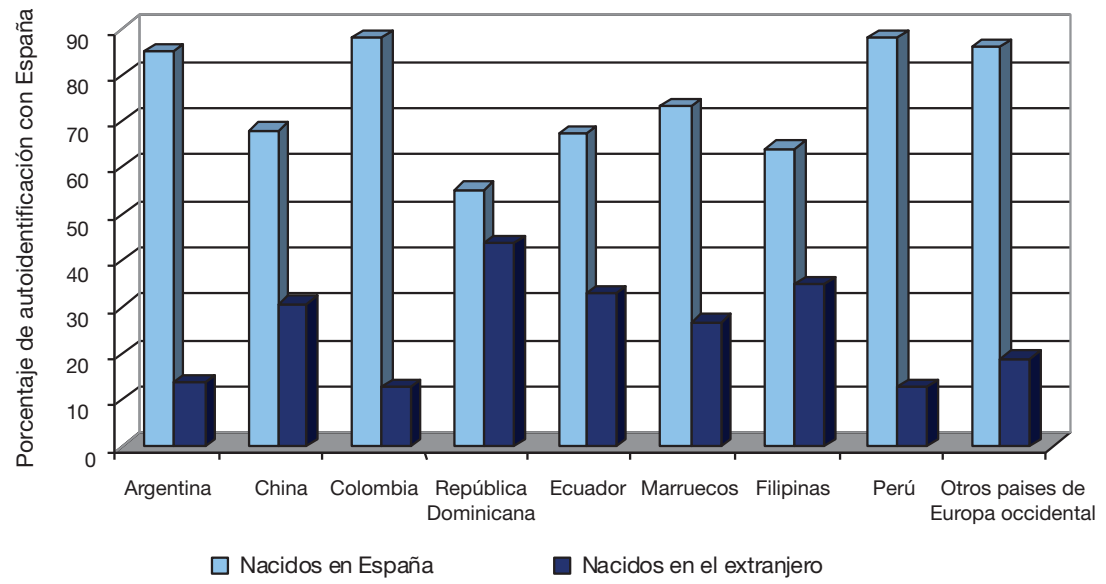

Fuente: Investigación Longitudinal de la Segunda Generación (ILSEG), 2008.

Aparecen excepciones adicionales cuando la atención se fija en los planes de futuro o en las opiniones sobre el país. Los chinos de segunda generación, por ejemplo, suelen mostrar las mismas ganas de vivir en el extranjero que sus coetáneos nacidos en China. Lo mismo ocurre con los filipinos y, en una medida un tanto menor, con los marroquíes. Es menos probable que los colombianos nacidos en España quieran quedarse en el país a que lo quieran sus compatriotas 
Figura 2. Planes residenciales por lugar de nacimiento para las diferentes nacionalidades en España (2008)

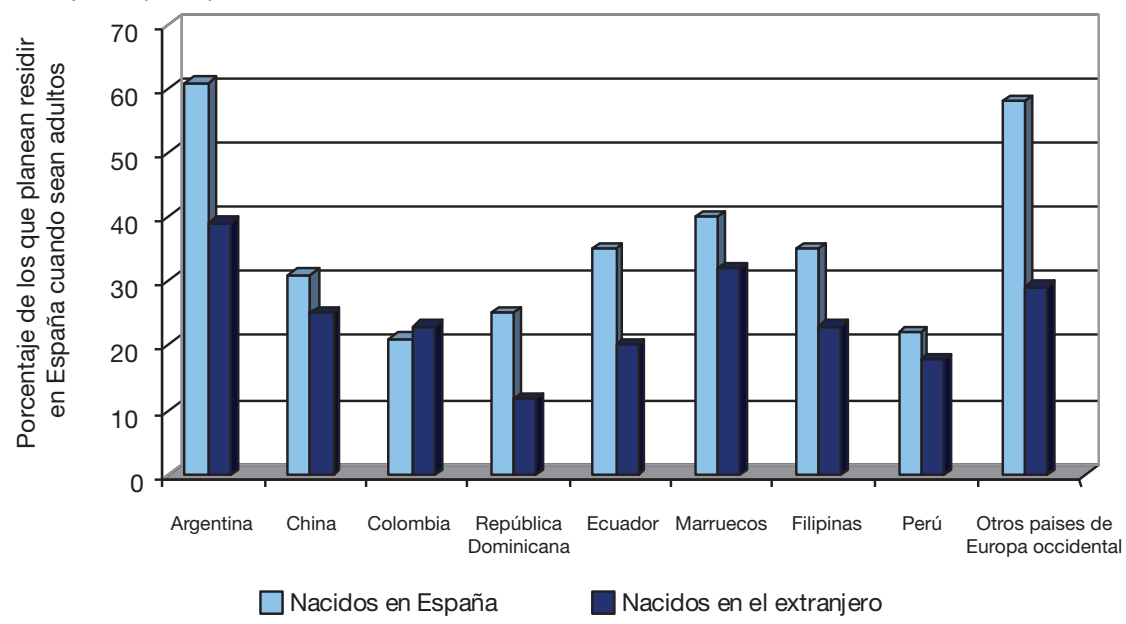

Fuente: Investigación Longitudinal de la Segunda Generación (ILSEG), 2008.

nacidos en el extranjero. Surgen unos resultados similares cuando la cuestión es la consideración de los extranjeros por parte de los españoles. Estas actitudes críticas apuntan, entre los nativos, a un compromiso poco uniforme con el país y a la probabilidad, al menos entre algunos de ellos, de la existencia de identidades reactivas u opositoras. A continuación, pasamos a examinar estas posibilidades.

\section{Resultados multivariables}

\section{a) Identificación nacional y actitudes hacia el país receptor}

La siguiente cuestión, lógicamente, es ¿cuáles son los determinantes de estos resultados sociopsicológicos? Para este análisis, utilizamos un par de variables. La primera es una dicotomía simple para indicar la autoidentificación como «español» (codificada 1) o como «otro» (codificada 0). La segunda es el resultado de un análisis factorial del resto de los ítems actitudinales examinados anteriormente. Uno de estos factores refleja una actitud claramente positiva hacia España y un deseo de quedarse y vivir en este país. La medida resultante, denominada «índice de actitud hacia España» (ATTSP en sus siglas en inglés) se compone de la suma de unidades ponderadas de los elementos con alto peso estadístico en este factor ${ }^{4}$.

4. Los ítems con una alta carga en este factor son las intenciones de vivir en España cuando se sea adulto y la aceptación de la afirmación que favorece a España como el mejor país para vivir. El análisis revela un segundo factor que refleja principalmente una tendencia a responder de acuerdo con la redacción de la pregunta. El rango del índice ATTSP es, por consiguiente, $0-2$. 
Con arreglo a las hipótesis provenientes del anterior repaso de la literatura, incluimos como predictores el lugar de nacimiento de los encuestados y de sus padres, el tiempo de residencia en el país ${ }^{5}$ y controles para la edad y el sexo. Incluimos también tres variables compuestas: el estatus socioeconómico familiar (FSES en sus siglas en inglés), que es la suma de los niveles estandarizados de educación del padre y de la madre y de los niveles ocupacionales del padre y de la madre ${ }^{6}$; el índice de conocimiento del español (KSI en sus siglas en inglés), que es la suma de la capacidad autoinformada de hablar, entender, leer y escribir el idioma, puesto que se ha demostrado que el conocimiento autoinformado de un idioma es un indicador fiable y válido en un gran número de contextos nacionales diferentes (Hakuta, 1986; Fishman, 1981; Lopez, 1982) (el coeficiente alfa para el KSI es 0,89 , lo que indica un alto nivel de consistencia interna en nuestra muestra), y, finalmente, el índice de relación intergeneracional (INTGEN), que es la suma de cuatro elementos dicotómicos que indican si los encuestados se sienten o no avergonzados de sus padres o si ven el mundo de formas similares. Unos niveles más elevados en el índice reflejan unas relaciones más positivas con los padres, lo que es indicativo de aculturación consonante o selectiva; unos niveles inferiores reflejan la probabilidad de una aculturación disonante ${ }^{7}$. Las experiencias de discriminación, otro posible determinante según la literatura, se miden mediante una única pregunta sobre la frecuencia con la que los encuestados se han sentido rechazados por otras personas. Una calificación alta refleja una mayor incidencia de dichas situaciones. Las estadísticas descriptivas de todas las variables del análisis se presentan en el apéndice.

Las columnas de la izquierda de la tabla 4 muestran los efectos de esta batería de predictores sobre las dos variables dependientes. Las columnas de la derecha añaden variables ficticias para todas las nacionalidades con al menos 100 casos en la muestra, para investigar si los orígenes nacionales específicos afectan a cada variable dependiente, una vez controlado el lugar de nacimiento. Los modelos utilizan la eliminación por lista de los datos no disponibles como el método más conservador y el que tiene menos posibilidades de introducir sesgos en los coeficientes de regresión. Varias rutinas de imputación, por lo general, exageran los $N$ y llevan a sobreestimar los niveles de significación. La tabla $4 a$ muestra regresiones logísticas anidadas de las autoidentidades nacionales para todos los predictores; la tabla $4 b$ muestra la distribución de los coeficientes logísticos multinomiales de las correspondientes regresiones para ATTSP $^{8}$. Exponenciamos los valores de todos los coeficientes significativos

5. Para los nacidos en España, esta variable es igual a su edad cronológica.

6. Todos los componentes del índice se estandarizaron a una media de 0 y una desviación estándar de 1. Su suma no ponderada se dividió entre cuatro, lo cual dio lugar a una media y a una desviación estándar similares. En los casos en los que faltaba información sobre uno o dos indicadores, la suma se dividió entre el número de los que quedaban.

7. El coeficiente alfa de consistencia interna para INTGEN es 0,552 , lo cual indica un nivel moderado de consistencia interna.

8. El índice de actitud hacia España es una variable ordinal con unos resultados elevados que indican una actitud más positiva hacia el país. 
Tabla 4. Determinantes de autoidentidades nacionales y actitudes hacia España entre los hijos de inmigrantes

\begin{tabular}{|c|c|c|c|c|c|c|}
\hline \multicolumn{7}{|c|}{ A. Autoidentificación como españoles } \\
\hline \multirow[b]{2}{*}{ Predictor } & \multicolumn{3}{|c|}{ I } & \multicolumn{3}{|c|}{ II } \\
\hline & Coef. ${ }^{1}$ & Wald & Exp. $\mathrm{B}^{2}$ & Coef. ${ }^{1}$ & Wald & Exp. $B^{2}$ \\
\hline Edad & $-0,237$ & $-7,0^{\star \star \star}$ & 0,79 & $-0,237$ & $-6,9^{\star \star \star}$ & 0,79 \\
\hline Sexo (femenino) & $-0,237$ & $-3,2^{\star \star}$ & 0,79 & $-0,257$ & $-3,4^{\star *}$ & 0,77 \\
\hline Ciudad de residencia (Barcelona) & 0,161 & 1,8 & - & 0,121 & 1,4 & \\
\hline Lugar de nacimiento (España) & 2,042 & $19,2^{\star \star \star}$ & 7,71 & 1,744 & $14,6^{\star \star \star}$ & 5,70 \\
\hline Tiempo de residencia en España & 0,102 & $9,6^{\star \star \star}$ & 1,11 & 0,104 & $9,5^{\star \star \star}$ & 1,11 \\
\hline Estatus familiar (FSES) & 0,224 & $4,5^{\star \star \star}$ & 1,25 & 0,169 & $3,2^{\star \star}$ & 1,18 \\
\hline Conocimiento del español (KSI) & 0,030 & 0,4 & - & 0,220 & $2,6^{*}$ & 1,25 \\
\hline Lugar de nacimiento del padre (España) & 1,181 & $7,5^{\star \star \star}$ & 3,26 & 1,311 & $8,1^{\star \star \star}$ & 3,71 \\
\hline Lugar de nacimiento de la madre (España) & 1,599 & $7,6^{\star \star \star}$ & 4,95 & 1,718 & $7,7^{\star \star \star}$ & 5,57 \\
\hline Relaciones intergeneracionales (IntGen) & 0,007 & 0,1 & - & $-0,005$ & $-0,1$ & - \\
\hline Experiencias de discriminación & $-0,071$ & $-1,1$ & - & $-0,118$ & $-1,8$ & - \\
\hline \multicolumn{7}{|l|}{ Origen nacional: } \\
\hline Argentina & & & & 0,167 & 0,8 & - \\
\hline Bolivia & & & & $-0,952$ & $-4,1^{\star \star \star}$ & 0,39 \\
\hline Colombia & & & & 0,330 & 1,4 & - \\
\hline República Dominicana & & & & $-0,660$ & $-4,2^{\star \star \star}$ & 0,52 \\
\hline Ecuador & & & & $-0,782$ & $-4,0^{\star \star \star}$ & 0,46 \\
\hline Marruecos & & & & $-0,659$ & $-5,7^{\star \star \star}$ & 0,52 \\
\hline Pakistán & & & & $-0,018$ & $-0,1$ & - \\
\hline Perú & & & & 0,810 & $2,3^{*}$ & 2,25 \\
\hline Filipinas & & & & $-0,076$ & $-0,5$ & - \\
\hline Rumanía & & & & 0,837 & $3,4^{\star \star}$ & 2,31 \\
\hline \multirow[t]{3}{*}{ Otros Europa occidental } & & & & 0,164 & 0,9 & - \\
\hline & & & & $-0,397$ & $-1,8$ & 一 \\
\hline & \multicolumn{3}{|c|}{$\begin{array}{r}\chi^{2}=1.201,69^{\star \star \star}(11 \text { d. f. }) \\
\text { Pseudo } R^{2}=0,201 \\
N=4.727\end{array}$} & \multicolumn{3}{|c|}{$\begin{array}{r}\chi^{2}=1.308,82^{\star \star \star}(23 \text { d. f. }) \\
\text { Pseudo } R^{2}=0,22 \\
N=4.723\end{array}$} \\
\hline
\end{tabular}

para facilitar su interpretación. Los valores exponenciales indicarían las probabilidades netas asociadas a cada predictor.

El predictor más potente de la autoidentidad nacional es el lugar de nacimiento, seguido por el tiempo de residencia en el país. Un niño nacido en España tiene unas probabilidades de casi ocho a una de identificarse como español. De manera similar, un niño nacido en el extranjero que ha vivido al menos diez años en el país tiene el doble de posibilidades de adoptar esta identidad. El lugar de nacimiento de los padres es también un sólido predictor, con unas probabilidades de identificación con el país de al menos tres a una a favor de aquéllos con un padre español. El estatus socioeconómico familiar tiene un efecto positivo más débil pero aún significativo.

Todos estos efectos son previsibles. Nacer en el país y un tiempo de residencia más largo en el mismo llevan, como se esperaba, a una identificación 
Tabla 4. Determinantes de autoidentidades nacionales y actitudes hacia España entre los hijos de inmigrantes (continuación)

\begin{tabular}{|c|c|c|c|c|c|c|}
\hline \multicolumn{7}{|c|}{ B. Actitud hacia España } \\
\hline \multirow[b]{2}{*}{ Predictor } & \multicolumn{3}{|c|}{1} & \multicolumn{3}{|c|}{ ॥I } \\
\hline & Coef. ${ }^{1}$ & Wald & Exp. $B^{4}$ & Coef. ${ }^{1}$ & Wald & Exp. $\mathrm{B}^{3}$ \\
\hline Edad & $-0,073$ & $-2,7^{\star \star}$ & 0,93 & $-0,069$ & $-2,6^{\star}$ & 0,97 \\
\hline Sexo (femenino) & $-0,334$ & $-5,6^{\star \star \star}$ & 0,72 & $-0,337$ & $-5,6^{\star \star \star}$ & 0,71 \\
\hline Ciudad de residencia (Barcelona) & $-0,042$ & $-0,6$ & & $-0,032$ & $-0,5$ & \\
\hline Lugar de nacimiento (España) & 0,504 & $5,6^{\star \star \star}$ & 1,66 & 0,465 & $4,6^{\star \star \star}$ & 1,59 \\
\hline Tiempo de residencia en España & 0,025 & $3,0^{\star \star}$ & 1,03 & 0,027 & $3,0^{\star \star}$ & 1,03 \\
\hline Estatus familiar (FSES) & $-0,048$ & $-1,2$ & - & $-0,052$ & $-1,2$ & \\
\hline Conocimiento del español (KSI) & $-0,132$ & $-2,1^{*}$ & 0,88 & $-0,106$ & $-1,6$ & \\
\hline Lugar de nacimiento del padre (España) & 0,592 & $4,7^{\star \star \star}$ & 1,81 & 0,619 & $4,7^{\star \star \star}$ & 1,86 \\
\hline Lugar de nacimiento de la madre (España) & 0,384 & $2,6^{\star \star}$ & 1,47 & 0,326 & $2,1^{*}$ & 1,39 \\
\hline Relaciones intergeneracionales (IntGen) & $-0,033$ & $-0,6$ & & $-0,048$ & $-0,9$ & \\
\hline$\underline{\text { Experiencias de discriminación }}$ & $-0,112$ & $-2,2^{*}$ & 0,89 & $-0,120$ & $-2,3^{*}$ & 0,89 \\
\hline \multicolumn{7}{|l|}{ Origen nacional: } \\
\hline Argentina & & & & $-0,038$ & $-0,2$ & \\
\hline Bolivia & & & & $-0,016$ & $-0,1$ & \\
\hline China & & & & 0,066 & 0,3 & \\
\hline Colombia & & & & $-0,287$ & $-2,2^{*}$ & 0,75 \\
\hline República Dominicana & & & & $-0,462$ & $-2,9^{\star \star}$ & 0,63 \\
\hline Ecuador & & & & $-0,126$ & $-1,3$ & \\
\hline Marruecos & & & & 0,057 & 0,4 & \\
\hline Pakistán & & & & 0,170 & 0,6 & \\
\hline Perú & & & & 0,038 & 0,3 & \\
\hline Filipinas & & & & $-0,341$ & $-1,6$ & \\
\hline Rumanía & & & & 0,198 & 1,3 & \\
\hline Otros Europa occidental & & & & 0,091 & 0,6 & \\
\hline & \multicolumn{3}{|c|}{$\begin{array}{r}\chi^{2}=156,32^{\star \star *}(11 \text { d. f. }) \\
\text { Pseudo } R^{2}=0,019 \\
N=4.577\end{array}$} & \multicolumn{3}{|c|}{$\begin{array}{r}\chi^{2}=182,18^{\star \star \star}(23 \text { d. f. }) \\
\text { Pseudo } R^{2}=0,022 \\
N=4.523\end{array}$} \\
\hline
\end{tabular}

1. Coeficientes de regresión logística binomial.

2. Probabilidades netas calculadas solo para efectos significativos.

3. Coeficientes ordenados de regresión multinomial.

4. Probabilidades netas calculadas solo para efectos significativos.

${ }^{*} p<0,05$

${ }^{\star *} p<0,01$

${ }^{\star \star \star} p<0,001$

Fuente: Investigación Longitudinal de la Segunda Generación (ILSEG), 2008.

con el país más fuerte; un estatus parental más elevado promueve la aculturación consonante o selectiva, lo cual lleva a un proceso de adaptación menos traumático. Sin embargo, resulta más sorprendente la influencia de la edad y el sexo. Los encuestados de mayor edad y las mujeres tienen significativamente menos probabilidad de autoidentificarse como españoles. Dado que el lugar de nacimiento, el tiempo de residencia y el estatus socioeconómico familiar se controlan, estas consecuencias no pueden ser atribuidas a una menor experien- 
cia en el país o a un bajo estatus parental. Las razones de estos efectos no son evidentes y recibirán más atención a continuación. Cabe mencionar también que mientras que la influencia de las experiencias de discriminación de las que se informó se da en la dirección esperada, resulta sin embargo estadísticamente insignificante. Las relaciones intergeneracionales tampoco afectan significativamente a las identidades nacionales.

La serie de variables ficticias asociadas a diferentes orígenes nacionales ofrece una curiosa historia: con algunas excepciones, los grupos latinoamericanos tienen considerablemente menos probabilidades de identificarse con España; sin embargo, los orígenes norteafricanos, europeos del Este y asiáticos no influyen o llevan a una mayor probabilidad de identificarse con el país. Estos resultados van en contra de lo que se esperaba, puesto que la afinidad más cercana de las culturas latinoamericanas con la española debería facilitar una transición psicológica más fluida. Sin embargo, encontramos que los jóvenes provenientes de orígenes culturales más distantes parecen mostrar una mayor predisposición a la hora de sustituir identidades. En términos generales, podría decirse que los adolescentes latinoamericanos tienen aproximadamente la mitad de probabilidades de verse como españoles que el resto de la muestra. Dado que se controla el lugar de nacimiento, estas diferencias no pueden ser completamente atribuidas a la presencia diferencial de nacidos en el extranjero entre distintas nacionalidades. No obstante, la comprensión del papel del origen nacional, así como el de la edad y el sexo, requiere un análisis más refinado, algo que se intenta en la siguiente sección.

Para mayor brevedad, no comentaremos todos los resultados de las regresiones multinomiales de la tabla $4 b$, dado que la configuración de los resultados es similar a la vista anteriormente. El nacimiento en España y un periodo más largo de residencia en este país producen unas actitudes significativamente más positivas, al igual que tener un padre o una madre nacidos en España. Las experiencias de discriminación se relacionan significativa y negativamente con las actitudes hacia el país. Las probabilidades de una postura positiva son inferiores entre aquéllos que, a menudo, han sufrido la discriminación. El enigma planteado por la influencia de la edad y el sexo persiste, dado que los jóvenes de mayor edad y las mujeres son significativamente más críticos. Curiosamente, aquéllos que muestran un mayor conocimiento del español son también más críticos, un resultado atribuible al predominio de los orígenes latinoamericanos entre los mismos. Una vez que se añaden las variables ficticias correspondientes al origen nacional, el efecto del lenguaje se vuelve insignificante. Nuevamente, los jóvenes de origen latinoamericano, particularmente los colombianos y los dominicanos, son significativamente más críticos con España. Otros orígenes nacionales no tienen ningún efecto una vez controladas las influencias del lugar de nacimiento, el tiempo de residencia en España y las todavía enigmáticas influencias de la edad y el sexo.

\section{b) Perfeccionando el análisis. Tendencias de los nacidos en España}

Estos resultados son válidos para el conjunto de la muestra. Sin embargo, tal y como hemos visto anteriormente, el $85 \%$ de ésta está formada por jóvenes 
nacidos en el extranjero, muchos de los cuales han estado viviendo en España solamente durante unos pocos años. El hecho de que no se identifiquen con el país o de que deseen volver al suyo es comprensible entre estos jóvenes. La situación de los nacidos en España - la «auténtica» segunda generación- es diferente y de ellos se puede esperar que manifiesten una asimilación identificacional mucho más fuerte. Tal y como muestran las conclusiones de la tabla 4 , esto es exactamente lo que ocurre en promedio, pero existen excepciones que indican la probabilidad de una postura más alienada o opositora, al menos entre algunos de los nacidos en el país. Para examinar esta posibilidad, replicamos el análisis en la muestra de encuestados nacidos en España $(N=816)$. El lugar de nacimiento y el tiempo de residencia se omiten, por tanto, en la serie de predictores. Eliminamos también todas las nacionalidades para las que el número de nacidos en el país es menor que 15 , dado que unas cifras inferiores producen coeficientes poco fiables. Al igual que en las regresiones anteriores, utilizamos la eliminación por lista como el método preferible para tratar los datos ausentes.

Los resultados se presentan en la tabla 5. Con la muestra restringida de este modo, ni la edad ni el sexo conservan una influencia significativa. Esto implica que los efectos observados anteriormente se debían a la fuerte propensión a no identificarse con España entre las jóvenes y los jóvenes de más edad nacidos en el extranjero. Una posible explicación de estos efectos es la mayor vinculación con sus familias de las jóvenes y de los jóvenes de más edad. En particular, es sabido que las jóvenes tienden a sentirse más vinculadas con sus padres y a verse más influidas por ellos, un factor que puede desempeñar un importante papel entre las niñas que han llegado más recientemente. Las variables clave para el aumento de la autoidentificación con España en la segunda generación propiamente dicha, son el mejor conocimiento del idioma y el hecho de que el padre o la madre hayan nacido en el país. La mayoría de los efectos del origen nacional desaparecen, lo cual indica que la mayor parte de los coeficientes observados anteriormente se debían al predominio de los nacidos fuera. Sólo existen tres excepciones: los hijos de padres peruanos y filipinos, que son significativamente más propensos a denominarse españoles, y los dominicanos de segunda generación, que continúan teniendo la mitad de probabilidades de hacerlo.

Los resultados de las regresiones multinomiales ordenadas del índice actitudinal hacia España (ATTSP) presentan ciertas pautas interesantes. Los jóvenes criados en Barcelona tienen significativamente menos probabilidad de mostrar actitudes positivas, lo que sugiere que absorben las posturas críticas de muchos catalanes frente al conjunto de España. Las mujeres e, interesantemente, los hijos de familias con un estatus superior también muestran actitudes más críticas. Este último resultado sugiere que una mejor educación asociada a un estatus parental más elevado puede derivar en una evaluación menos optimista de las posibilidades de futuro en el país. Esta conclusión se ve reforzada por los coeficientes negativos asociados a varios grupos nacionales, incluidos aquéllos que, como los filipinos, tienen más probabilidad de identificarse como españoles. No obstante, ha de tenerse en cuenta que estas variaciones son internas a la 
Tabla 5. Predictores de autoidentidades y actitudes hacia España entre jóvenes nativos (2008)

\begin{tabular}{|c|c|c|c|}
\hline \multicolumn{4}{|c|}{ A. Autoidentificación como españoles } \\
\hline Predictor I & Coef. ${ }^{1}$ & Wald & Exp. $\mathrm{B}^{2}$ \\
\hline Edad & $-0,081$ & $-0,9$ & - \\
\hline Sexo (femenino) & 0,162 & 0,8 & - \\
\hline Ciudad de residencia (Barcelona) & $-0,264$ & $-1,2$ & - \\
\hline Estatus familiar (FSES) & $-0,099$ & $-0,9$ & \\
\hline Conocimiento del español (KSI) & 0,596 & $2,2^{\star \star}$ & 1,81 \\
\hline Lugar de nacimiento del padre (España) & 1,138 & $3,8^{\star \star \star}$ & 3,12 \\
\hline Lugar de nacimiento de la madre (España) & 1,580 & $5,0^{\star \star \star}$ & 4,86 \\
\hline Relaciones intergeneracionales (IntGen) & 0,047 & 0,3 & - \\
\hline Experiencias de discriminación & $-0,046$ & 0,3 & - \\
\hline \multicolumn{4}{|l|}{ Origen nacional: } \\
\hline Argentina & 0,456 & 0,8 & \\
\hline China & 0,384 & 0,8 & 0,51 \\
\hline Colombia & 0,832 & 0,8 & \\
\hline República Dominicana & $-0,671$ & $-1,8 \#$ & \\
\hline Ecuador & $-0,238$ & $-0,4$ & \\
\hline Marruecos & 0,043 & $-0,2$ & \\
\hline Pakistán & 0,286 & 0,3 & \\
\hline Perú & 1,109 & $2,1^{*}$ & 3,03 \\
\hline Filipinas & 0,805 & $-0,4$ & 2,24 \\
\hline \multirow[t]{2}{*}{ Otros Europa occidental } & $-0,119$ & $2,0^{\star}$ & \\
\hline & & \multicolumn{2}{|c|}{$\begin{array}{r}\chi^{2}=69,27^{\star \star \star}(20 \text { d. f. }) \\
\text { Pseudo } R^{2}=0,089 \\
N=731\end{array}$} \\
\hline
\end{tabular}

muestra de nacidos en España, la cual, tomada en su conjunto, es significativa y fuertemente más propensa a identificarse con el país y a mostrar actitudes más positivas hacia el mismo.

El único indicio de actitudes reactivas o de oposición ha sido encontrado entre los jóvenes de origen dominicano. Su resistencia frente a la autoidentificación como españoles no se debe a que la gran mayoría naciera en el extranjero, ya que cerca del 20\% (67 casos) nació en España. Como acabamos de ver, estos nativos dominicanos siguen mostrando posturas negativas frente a España, incluso después de controlar otros predictores. En un intento de clarificar este resultado, relacionamos el origen dominicano con todos los demás predictores fundamentales que hemos identificado anteriormente. Los resultados (no mostrados) indican que, entre los nativos, la única interacción significativa tiene que ver con el sexo: la probabilidad de que una mujer dominicana nacida en España se sienta identificada con el país es solo de una de diez posibilidades $(p<0,05)$. Cuando se controla esta interacción, los efectos principales, tanto del género como del origen dominicano, se tornan insignificantes. También volvimos sobre los cuestionarios originales y descubrimos que muchos de los encuestados dominicanos habían escrito notas quejándose del rechazo exterior sufrido a causa de 
Tabla 5. Predictores de autoidentidades y actitudes hacia España entre jóvenes nativos (2008) (continuación)

\begin{tabular}{|c|c|c|c|}
\hline \multicolumn{4}{|c|}{ B. Actitudes hacia España } \\
\hline Predictor & Coef. ${ }^{1}$ & Wald & Exp. $B^{2}$ \\
\hline Edad & $-0,171$ & $-2,4^{*}$ & 0,84 \\
\hline Sexo (femenino) & $-0,389$ & $-2,6 \#$ & 0,68 \\
\hline Ciudad de residencia (Barcelona) & $-0,415$ & $-2,5^{\star}$ & 0,66 \\
\hline Estatus familiar (FSES) & $-0,287$ & $-3,1^{\star \star}$ & 0,75 \\
\hline Conocimiento del español (KSI) & $-0,032$ & $-0,01$ & \\
\hline Lugar de nacimiento del padre (España) & 0,539 & $2,5^{\star}$ & 1,71 \\
\hline Lugar de nacimiento de la madre (España) & 0,360 & $1,8 \#$ & 1,44 \\
\hline Relaciones intergeneracionales (IntGen) & 0,160 & 1,2 & \\
\hline Experiencias discriminación & $-0,122$ & $-1,0$ & \\
\hline \multicolumn{4}{|l|}{ Origen nacional: } \\
\hline Argentina & 0,385 & 1,0 & \\
\hline China & $-0,373$ & $-0,9$ & \\
\hline Colombia & $-1,339$ & $-2,1^{*}$ & 0,26 \\
\hline República Dominicana & $-1,152$ & $-3,1^{\star \star}$ & 0,32 \\
\hline Ecuador & $-0,223$ & $-0,4$ & \\
\hline Marruecos & $-0,516$ & $-2,1^{\star}$ & 0,60 \\
\hline Pakistán & 0,187 & 0,3 & \\
\hline Perú & $-0,168$ & 0,5 & \\
\hline Filipinas & $-0,886$ & $-2,8^{\star \star}$ & 0,41 \\
\hline \multirow[t]{2}{*}{ Otros Europa occidental } & 0,228 & 1,0 & \\
\hline & & \multicolumn{2}{|c|}{$\begin{array}{r}\chi^{2}=85,13^{\star \star \star}(21 \text { d. f. }) \\
\text { Pseudo } R^{2}=0,059 \\
N=705\end{array}$} \\
\hline
\end{tabular}

1. Coeficientes ordenados de regresión logística multinomial.

2. Probabilidades netas calculadas solo para efectos significativos.

$\# \mathrm{p}<0,10$

${ }^{*} \mathrm{p}<0,05$

${ }^{\star \star} p<0,01$

*** $p<0,001$

Fuente: Investigación Longitudinal de la Segunda Generación (ILSEG), 2008.

su raza. Esto era especialmente notable entre las mujeres: «Me decían cosas feas por la calle», escribió una encuestada y otra se sintió rechazada por su profesor "porque soy negra», una queja expresada por varias de sus iguales.

En su estudio sobre jóvenes dominicanos de segunda generación en Boston, Bailey $(2000,2001)$ concluyó que éstos luchaban contra el hecho de que se les identificara con afroamericanos hablando español a voz en grito, a fin de respaldar su derecho a ser identificados como «hispanos». Esta herramienta de autodefensa puede funcionar bien en los Estados Unidos, pero, como es evidente, no en España. Al verse incapaces de evitar que la gran mayoría blanca les identifique como negros, los jóvenes dominicanos residentes en España reaccionan reafirmando fuertemente su origen nacional y adoptando una postura crítica frente a la sociedad anfitriona. Por razones que están aún por clarificarse, esta reacción aparece con más fuerza entre las mujeres. 


\section{c) Determinantes de la autoestima}

Junto con las autoidentidades, la autoestima representa otro importante capítulo sociopsicológico en el proceso de adaptación (Golash-Boza, 2006; Rumbaut, 2005). Las cuestiones clave en lo que a esto se refiere son el nivel medio de autoestima entre los hijos de inmigrantes, sus principales determinantes y hasta qué punto difieren de los predictores de la autoidentidad y de las actitudes hacia la sociedad anfitriona. El cuestionario contiene una traducción al español del índice de autoestima de Rosenberg (1965). Este índice es el instrumento que se utiliza con mayor frecuencia para medir tal dimensión entre la población adolescente. Un análisis factorial de los diez elementos que lo componen, tanto en Madrid como en Barcelona, produjo una clara estructura unidimensional en la que casi todos los elementos cargaban significativamente en el primer factor. Además, la consistencia interna (alfa de Cronbach) alcanzó el 0,732 en Madrid y el 0,694 en Barcelona. Estos resultados respaldan al índice como un indicador transnacionalmente fiable de la autoestima.

Los valores del índice van del 1 al 4 (la autoestima más alta se indica con una puntuación más alta). El valor promedio en la muestra total es 2,97, lo que sugiere un nivel moderadamente alto. Esta media no varía mucho entre ciudades (3,01 en Madrid y 2,93 en Barcelona), tipos de escuela (2,94 para las privadas y 3,00 para las públicas) o lugar de nacimiento (2,96 para los nacidos en el extranjero y 3,07 para los nativos). Todas estas diferencias son estadísticamente significativas, pero esto se debe esencialmente al gran tamaño de la muestra.

Como predictores de la autoestima, utilizamos la misma batería de variables enumeradas anteriormente, añadiendo la de autoidentificación nacional. A pesar de que la relación causal entre ambas variables resulta ambigua, la presencia o ausencia de una asociación una vez controladas otras variables representa una información útil. Se anidan, como antes las regresiones, añadiendo en la columna de la extrema derecha las variables ficticias de origen nacional. En este caso, la variable dependiente se mide con una escala de intervalo. Por consiguiente, utilizamos una regresión ordinaria de mínimos cuadrados y, como anteriormente, tratamos los datos no disponibles mediante eliminación por lista.

Los resultados se presentan en la tabla 6. La ordenación de los efectos es, en este caso, bastante diferente de la observada para la autoidentidad. El determinante más fuerte es, con mucho, el de las relaciones intergeneracionales (INTGEN), cuyos efectos exceden en 23 veces su error estándar. La autoestima se incrementa en un cuarto neto de puntos por cada punto adicional en INTGEN. El siguiente efecto más fuerte es el del dominio del español (KSI), en el que cada punto adicional (en un rango del 1 al 4) incrementa la autoestima en 0,15 . Este efecto es también altamente fiable y excede 12 veces su error estándar. El coeficiente siguiente en importancia estadística corresponde a las experiencias de discriminación sufridas en el pasado, el cual reduce considerablemente la autoestima. 
Tabla 6. Determinantes de autoestima entre hijos de inmigrantes en España (2008)

\begin{tabular}{|c|c|c|c|c|}
\hline \multirow[b]{2}{*}{ Predictores } & \multicolumn{2}{|c|}{1} & \multicolumn{2}{|c|}{ ॥ } \\
\hline & Coef. ${ }^{1}$ & Valor t & Coef. ${ }^{1}$ & Valor $\mathrm{t}$ \\
\hline Edad & 0,011 & $2,0^{*}$ & 0,010 & 1,9 \\
\hline Sexo (femenino) & $-0,034$ & $-2,9^{\star \star}$ & $-0,033$ & $-2,9^{\star \star}$ \\
\hline Ciudad de residencia (Barcelona) & $-0,049$ & $3,7^{\star \star \star}$ & $-0,045$ & $-3,3^{\star \star}$ \\
\hline Lugar de nacimiento (España) & 0,036 & $1,9^{*}$ & 0,045 & $2,1^{*}$ \\
\hline Tiempo de residencia en España & 0,001 & 0,4 & 0,001 & 0,4 \\
\hline Lugar de nacimiento del padre (España) & 0,030 & 1,2 & 0,012 & 0,5 \\
\hline Lugar de nacimiento de la madre (España) & 0,013 & 0,4 & $-0,014$ & $-0,4$ \\
\hline Estatus familiar (FSES) & 0,047 & $5,8^{\star \star \star}$ & 0,042 & $4,9^{\star \star \star}$ \\
\hline Conocimiento del español (KSI) & 0,148 & $12,11^{\star \star \star}$ & 0,146 & $11,2^{\star \star \star}$ \\
\hline Relaciones intergeneracionales (IntGen) & 0,255 & $23,9^{\star \star \star}$ & 0,53 & $23,6^{\star \star \star}$ \\
\hline Experiencias discriminación & $-0,091$ & $-9,3^{\star \star \star}$ & $-0,094$ & $-9,4^{\star \star \star}$ \\
\hline Autoidentificación española & 0,014 & 0,9 & 0,015 & 1,0 \\
\hline \multicolumn{5}{|l|}{ Origen nacional: } \\
\hline Argentina & & & $-0,003$ & $-0,1$ \\
\hline Bolivia & & & $-0,073$ & $-2,4^{\star}$ \\
\hline China & & & 0,006 & $-0,2$ \\
\hline Colombia & & & 0,010 & 0,4 \\
\hline República Dominicana & & & $-0,001$ & 0,1 \\
\hline Ecuador & & & $-0,032$ & $-1,7$ \\
\hline Marruecos & & & $-0,040$ & $-1,5$ \\
\hline Pakistán & & & $-0,066$ & $-1,0$ \\
\hline Perú & & & $-0,019$ & $-0,7$ \\
\hline Filipinas & & & $-0,125$ & $-3,0^{\star \star}$ \\
\hline Rumanía & & & 0,011 & 0,4 \\
\hline Otros de Europa occidental & & & 0,028 & 0,9 \\
\hline \multirow[t]{2}{*}{ Constante } & 1,636 & $16,8^{\star \star \star}$ & 1,674 & $16,7^{\star \star \star}$ \\
\hline & & $\begin{aligned} R^{2} & =0,201 \\
N & =4.704\end{aligned}$ & & $\begin{aligned} R^{2} & =0,205 \\
N & =4.700\end{aligned}$ \\
\hline
\end{tabular}

1. Coeficientes de regresión ordinaria de mínimos cuadrados (no estandardizados).

${ }^{*} \mathrm{p}<0,05$

$* \star p<0,01$

$\star * \star *<0,001$

Fuente: Investigación Longitudinal de la Segunda Generación (ILSEG), 2008.

Con estos tres predictores controlados, el lugar de nacimiento de los encuestados ejerce solo una influencia tangencial y los del lugar de nacimiento de los padres pasan a ser insignificantes. La autoidentidad nacional no ejerce efecto alguno en la autoestima, lo que indica la ausencia de una relación entre las dos dimensiones psicosociales. Este resultado puede deberse a que las autoidentidades se ajustan para proteger la autoestima, de manera que se pueden encontrar niveles de autoestima similares entre jóvenes con identificaciones nacionales muy diversas. En investigaciones anteriores, Altschul et al. (2008), San Juan (2005), Ono (2002) y otros investigadores demostraron que jóvenes inmigrantes que se percibían discriminados reaccionaban enérgicamente 
cambiando sus autoidentidades como medio para preservar su sentido de la autoestima.

Otros efectos notables son los del estatus socioeconómico familiar, que aumenta considerablemente la autoestima, así como el sexo (femenino) que lo reduce. Los niveles de autoestima inferiores entre las mujeres coinciden con las conclusiones de la literatura estadounidense, incluyendo estudios sobre los adolescentes de segunda generación (Feliciano y Rumbaut, 2005; Portes y Rumbaut, 2001, cap. 8). Tales estudios mostraron sistemáticamente unos niveles de autoestima inferiores entre las adolescentes, a pesar de sus aspiraciones y sus logros académicos más elevados. Curiosamente, los niveles superiores de autoestima encontrados a nivel bivariante entre los nacidos en España y entre los residentes en Madrid continúan siendo importantes. El efecto del nacimiento en España es razonable y refuerza el del dominio del idioma. Sin embargo, las razones del más bajo nivel de autoestima en la muestra de Barcelona no son evidentes.

La adición de las variables ficticias de origen nacional no modifica estos resultados ni tampoco incrementa su poder explicativo. El coeficiente de determinación $R^{2}$ continúa siendo el mismo y sólo unos pocos coeficientes nacionales adquieren significatividad. La lectura principal de la tabla 6 es que los determinantes de la autoestima entre los hijos de inmigrantes en España son fundamentalmente relacionales. Una buena relación con los padres eclipsa todo lo demás, incluida la influencia del estatus socioeconómico familiar. Malas relaciones externas, reflejadas por la discriminación sufrida en el pasado, afectan también a la autoestima de manera decisiva. Por último, poseer un dominio del idioma del país contribuye marcadamente a fortalecer la autoimagen de los jóvenes. Al controlar estas variables, la mayoría de los predictores de autoidentidad nacional, así como la autoidentidad misma, dejan de ejercer cualquier efecto. Ello indica que los procesos determinantes de las dos dimensiones psicosociales son diferentes.

\section{Un modelo estructural de la adaptación psicosocial}

Tras haber examinado por separado las autoidentidades nacionales y la autoestima, lo que ahora buscamos es integrar los resultados en un modelo único que proporcione una representación teórica unificada de nuestros resultados. Con este fin, hacemos uso de modelos de ecuaciones estructurales (SEM) calculados mediante las rutinas AMOS y MPLUS. Toda teoría lleva implícita una simplificación y nuestro caso no constituye una excepción. Por consiguiente, no pretendemos incluir en el modelo todos los resultados individuales tratados anteriormente, sino tan solo los más importantes desde un punto de vista teórico y práctico. Este modelo pretende reproducir los determinantes de dos dimensiones: la de orientación nacional, definida como una variable latente calculada empíricamente mediante dos indicadores, y la de autoestima, definida mediante las puntuaciones del índice de Rosenberg. El modelo se presenta en la figura 3. 
Figura 3. Un modelo estructural de los resultados psicosociales en la segunda generación de España ${ }^{1}$

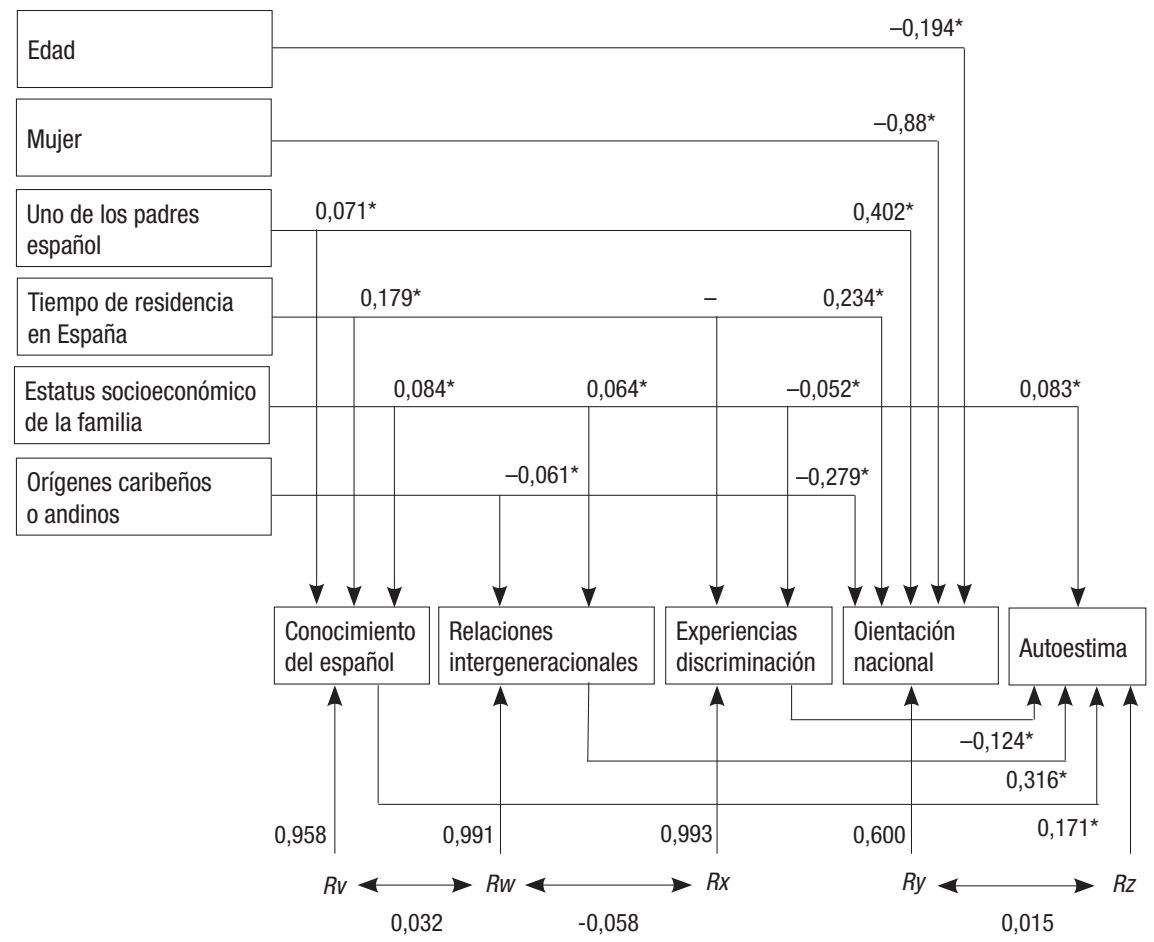

$\mathrm{NFI}=0,860 ; \mathrm{IFI}=0,864 ; \mathrm{TLI}=0,800 ; \mathrm{RMSEA}=0,051$

1. Las cifras en las flechas unidireccionales que salen de variables encuadradas representan coeficientes de regresión estandarizados. Aquellas en las flechas bidireccionales representan correlaciones. Los coeficientes adjuntos a flechas con subindicadores alfabéticos representan varianzas residuales. $\left(1-R^{2}\right)$ Estimaciones MPLUS.

${ }^{*} p<0,001$

Los resultados previos de las tablas $4 b$ y $5 b$ muestran que nuestra medida actitudinal (ATTSP) se ve influida tanto por la autoidentificación nacional como por la evaluación realista de las condiciones del país, según lo indica, entre otras cosas, la influencia negativa del estatus familiar. Con la presente estimación, buscamos centrarnos en la identificación nacional propiamente dicha y, con este fin, definimos a ésta como una variable latente que afecta a los dos indicadores empíricos conceptualmente más cercanos a ella: la autoidentificación como españoles y la intención de vivir en España cuando se llegue a la adultez.

El modelo incluye, como variables exógenas, la edad, el sexo, el estatus socioeconómico de la familia y el tiempo de residencia en España. Como se ha observado en el análisis previo, tanto el lugar de nacimiento como el tiempo de residencia en el país tienen un fuerte efecto sobre las autoidentidades, pero 
se descarta su inclusión simultánea en el modelo, dada su fuerte colinearidad. Nos inclinamos por la duración de la residencia por su carácter de variable continua y su inclusión del total de la muestra ${ }^{9}$. La lista de variables exógenas incluye también un indicador integrado del lugar de nacimiento de los padres, codificado con un 1 si alguno de los padres nació en España y con un 0 en el caso contrario. Por último, los orígenes nacionales también se incluyen como dicotomía, puesto que reflejan la significativa influencia negativa sobre la identificación con España entre ciertas nacionalidades caribeñas y andinas. Esta variable se codifica con un 1 si el hijo o sus padres nacieron en la República Dominicana, Bolivia, Colombia o Ecuador y con un 0 en el caso contrario ${ }^{10}$.

La direccionalidad causal de los efectos de esta serie de variables exógenas no es problemática, puesto que no es verosímil que las autoidentidades y la autoestima de los adolescentes puedan determinar el lugar de nacimiento de los padres, el estatus familiar o su origen nacional. El modelo incluye, como variables intermedias que afectan principalmente a la autoestima, el dominio del español (KSI), el índice de relaciones intergeneracionales (INTGEN) y las experiencias previas de discriminación. Mientras que es posible que los niveles de autoestima puedan afectar a estas variables, la lógica teórica y el peso de las investigaciones anteriores indican que la direccionalidad causal va en el sentido opuesto. Resulta más verosímil, por ejemplo, que las relaciones paterno-filiales afecten a la autoestima de los adolescentes que la relación ocurra en el sentido opuesto. El caso del dominio del español es el mismo. Por esta razón, el modelo de la figura 3 se define como totalmente recursivo.

Para la convergencia del modelo en ambas estimaciones, el valor de uno de los indicadores de la variable latente, "Orientación nacional», se fijó en 1. El efecto más fuerte sobre esta variable resultó ser el lugar de nacimiento de los padres, cuyo coeficiente en la estimación MPLUS excede en 21 veces su error estándar. En ambas estimaciones, el hecho de tener un padre nacido en España incrementa la orientación positiva hacia el país en, al menos, medio punto ${ }^{11}$. Le sigue la influencia de los orígenes andino-caribeños, que alcanza a ser casi quince veces su error estándar, pero discurriendo en la dirección contraria. La edad y el sexo (femenino) llevan también a experimentar una orientación española significativamente inferior, mientras que el tiempo de residencia lo aumenta considerablemente: en el modelo MPLUS. Cada año adicional en España produce un aumento de 0,02 en la escala de orientación nacional.

La autoestima se determina mediante un conjunto de predictores completamente diferente. De hecho, las dos variables dependientes no tienen ni una sola causa en común en este modelo y su correlación residual es mínima. El predictor más sólido de la autoestima es «relaciones intergeneracionales», cuyo coeficiente en ambas estimaciones excede 23 veces su error estándar.

9. Véase la nota número 6.

10. Se excluye Perú, puesto que, tal y como se puede observar en las tablas 4 y 5 , los efectos de esta nacionalidad en la autoidentidad son sistemáticamente insignificantes.

11. La escala de la variable latente de orientación nacional es de 1-4. 
Cada aumento de un punto en el índice INTGEN conlleva el correspondiente aumento neto de un cuarto de punto $(0,25)$ en la escala de autoestima. El dominio del español (KSI) y el estatus socioeconómico familiar tienen también un fuerte efecto positivo en la autoestima, mientras que las experiencias previas de discriminación lo reducen significativamente.

En términos generales, el modelo es eficiente para explicar las principales tendencias causales reflejadas por los datos, como lo indican los efectos residuales de los predictores de una de las dos variables dependientes sobre la otra. Estos efectos (que no se muestran) son, sin excepción alguna, insignificantes. La varianza explicada es también considerable para ambas dimensiones: los coeficientes $R^{2}$ para la orientación nacional son de 0,388 en el modelo AMOS y de 0,400 en el MPLUS. En cuanto a la autoestima, los coeficientes son, respectivamente, de 0,203 y 0,190. La varianza explicada en las variables intervinientes es mucho más baja. Sin embargo, esto es menos relevante a efectos teóricos del modelo y se compensa por su parsimonia: utiliza solo 29 de los 51 grados de libertad disponibles.

Por esta razón, los diagnósticos para el modelo, aunque no son perfectos, se encuentran dentro de límites aceptables: el índice de ajuste normalizado Delta 1 (NFI Delta 1) se acerca al 0,90 (0,860), así como el IDI de Bollen (0,864 en comparación con 1,000 del modelo saturado). El TLI en el MPLUS es de 0,80 , mientras que la comúnmente utilizada raíz cuadrada media del error de aproximación de Steiger (RMSEA), medida que tiene en cuenta la parsimonia del modelo, alcanza un admisible criterio de 0,05 (Maruyama, 1998). El modelo permite la correlación de residuales entre todas las variables endógenas. Tal y como se ha observado, la correlación entre los dos resultados finales se encuentra próxima a cero, mientras que las que se dan entre las tres variables intervinientes son algo superiores, pero también modestas.

\section{Conclusión}

La inmigración masiva de las últimas décadas del siglo XX y la incipiente inmigración del siglo XXI han tenido unos efectos muy importantes en las sociedades de recepción, puesto que han modificado sus demografías, la composición de su mano de obra y la imagen y el ambiente de sus ciudades. Una de las consecuencias más importantes a largo plazo ha sido la aparición, en las naciones anfitrionas, de una segunda generación, en la mayoría de los casos con derecho a la ciudadanía, que constituye un porcentaje cada vez mayor de su población de jóvenes. Esta segunda generación plantea una serie de desafíos a las sociedades y a los gobiernos receptores, los cuales deben intentar integrar y educar a sus miembros para que se conviertan en ciudadanos productivos y respetuosos de la ley. En la mayoría de los casos, las investigaciones y las teorías sobre los hijos de inmigrantes actuales y futuros se han llevado a cabo en los Estados Unidos, a pesar de que existe cada vez más literatura sobre el tema en la Europa occidental. Sin embargo, la mayoría de los estudios europeos se han basado en muestras no representativas. 
En este artículo, buscamos contribuir a esta incipiente literatura recurriendo a una muestra amplia y estadísticamente representativa de los jóvenes de segunda generación de las dos ciudades más grandes de España: Madrid y Barcelona. La encuesta corresponde a la primera fase de un estudio longitudinal que pretende seguir a esta población a lo largo del tiempo hasta su adultez temprana. En consecuencia, la encuesta se concentró en la población adolescente con una edad media de 14 años. Por este motivo, las conclusiones sobre su adaptación no son finales, sino que se componen de un conjunto de variables intermedias, principalmente de corte sociopsicológico. De éstas, seleccionamos, para el análisis, la autoidentidad, las actitudes hacia la nación anfitriona y la autoestima. Cabe admitir que estas orientaciones subjetivas son maleables y pueden cambiar con el paso del tiempo. Sin embargo, son importantes por varias razones.

La autoidentidad es importante no sólo para los propios individuos, sino también, bajo ciertas condiciones, para la sociedad anfitriona. Las autoidentidades pueden proveer una base para solidaridades, formas comunes de ver el mundo y, en ocasiones, para movilizaciones masivas de protesta - como, por ejemplo, ocurrió en el caso de las revueltas de jóvenes inmigrantes en las ciudades francesas en 2005 (Schneider, 2008). Por el contrario, la identificación con la sociedad anfitriona representa una señal clara de integración y establece una base para la prosecución de caminos de movilidad ascendente dentro de ella. Por su parte, la autoestima se ha asociado sistemáticamente con resultados académicos positivos y se ve influida, a su vez, por la calidad de las relaciones con los padres y por experiencias previas de aceptación o rechazo en la sociedad anfitriona.

Nuestro análisis revela un resultado anómalo inicial: la mayoría de los hijos de inmigrantes en España ni se sienten identificados con el país ni desean vivir en él cuando sean adultos. Esta conclusión aparentemente alarmante se ve explicada, en gran parte, por la composición de la muestra, puesto que, en ella, la gran mayoría son miembros de la generación 1,5 - nacidos en el extranjero y traídos a España a una edad temprana. Una vez se tiene en cuenta este factor, la situación cambia considerablemente, pues una mayoría significativa de la segunda generación nacida en España se autoidentifica como española. Aun así, más de la mitad de los miembros de este grupo no tienen pensado vivir en el país cuando sean adultos y sólo una tercera parte piensa que España es el mejor país para vivir. Estos resultados indican que, junto con la sólida identificación con el país como «suyo», la mayoría de los hijos de inmigrantes nacidos en España tienden a tener un punto de vista bastante pesimista acerca de sus oportunidades de futuro en él. La entrada relativamente reciente de España en el rango de los países desarrollados y las escasas oportunidades de su mercado laboral, en comparación con los países más ricos de la Europa occidental y los Estados Unidos, es causa probable de estas percepciones (Cachón, 2009).

No obstante, nuestro análisis demuestra que nacer en España, tener un padre nativo y contar con más tiempo de residencia llevan a una mayor identificación con el país y a una actitud más positiva hacia el mismo. Ésta es una sólida 
prueba contra los temores de que la segunda generación no se esté integrando debidamente. La resistencia a la autoidentificación como españoles es mayor entre los encuestados de mayor edad, las mujeres y los adolescentes de origen caribeño y andino. Estos resultados son atribuibles también al nacimiento en el extranjero y a una llegada reciente al país de la mayoría de la muestra y, por consiguiente, no parecen ser señal de una tendencia a largo plazo: las influencias negativas del sexo y la edad en la autoidentidad como españoles desaparece entre los nacidos en el país, al igual que la mayoría de los efectos asociados a los orígenes nacionales. La única excepción es la de los jóvenes dominicanos que, incluso cuando han nacido en España, siguen resistiéndose a identificarse con el país. Atribuimos este resultado a una postura reactiva entre la mayoría de los jóvenes dominicanos negros o mulatos ante el racismo percibido en la población blanca nativa y a la falta de otros medios de defensa (Bailey, 2001).

La autoestima y la autoidentificación nacional no están correlacionadas. Este resultado se debe, probablemente, al ajuste de las autoidentificaciones nacionales y étnicas precisamente para proteger la autoestima. Para la muestra en su conjunto, la media de la autoestima es razonablemente alta. Sin embargo, a pesar de cualesquiera ajustes que se hagan en las autoidentidades, las experiencias previas de discriminación reducen significativamente la autoestima. Por el contrario, buenas relaciones con los padres y el pleno dominio del idioma del país la incrementan. Para la muestra en su conjunto, los orígenes andinocaribeños ejercen una influencia negativa indirecta en la autoestima a través de su efecto negativo sobre las relaciones intergeneracionales.

Este último efecto es uno de los muchos captados por un modelo estructural integrado que busca representar las principales pautas causales en estos datos. El modelo en la figura 3 proporciona una síntesis gráfica de los determinantes de las dimensiones psicosociales en la segunda generación, puesto que incluye a todos sus componentes. Un modelo similar limitado a la minoría de los jóvenes nacidos en España resultaría totalmente diferente, dado que, en él, desaparecerían las influencias negativas sobre las autoidentidades de la edad, el sexo y los orígenes andino-caribeños.

Por último, y para poner estos resultados en una perspectiva comparada, podemos relacionarlos con los del Estudio Longitudinal sobre Hijos de Inmigrantes (CILS en sus siglas en inglés) realizado en los Estados Unidos y en el cual se ha inspirado el presente estudio (Portes y Rumbaut, 2001). El principal resultado de este ejercicio es mostrar que, a pesar de los muy diferentes contextos nacionales y de los quince años transcurridos entre las respectivas encuestas, los resultados de ambos estudios son muy similares. Para citar solo unas cuantas de estas similitudes:

1) Solo el 35\% de los jóvenes nacidos en el extranjero en la encuesta inicial del CILS (con una edad media de 14 años) se identificaba como "americano» (con identidades múltiples o no); la cifra aumentaba al 69\% entre los jóvenes nacidos en EE. UU., lo cual anticipa la pauta observada en España (Rumbaut, 1996: 136). 
2) En ambos estudios, el lugar de nacimiento de los padres ejerce una influencia decisiva sobre las autoidentificaciones: entre aquéllos que se identificaban con una nacionalidad extranjera en los Estados Unidos, cerca del 90\%, tenían padres nacidos en el mismo país extranjero; las identidades extranjeras caían a un diminuto 5\% entre aquéllos con un padre nacido en los Estados Unidos (Portes y Rumbaut, 2001: 165).

3) La autoestima, medida por el índice de Rosenberg, es algo superior entre los jóvenes de segunda generación en los Estados Unidos $(\bar{x}=3,29)$. Sin embargo, el proceso causal que lleva a ella es básicamente el mismo en ambos países: las mujeres muestran una autoestima significativamente inferior, así como los jóvenes que experimentaron discriminación reiteradamente en el pasado. Como en España, los niveles de autoestima se vieron incrementados en la muestra del CILS por la fluidez en el idioma del país anfitrión y por una relación positiva con los padres (Rumbaut, 1996: 143; Portes y Rumbaut, 2001: tabla 8.6).

Estas similitudes son importantes desde el punto de vista teórico, puesto que apoyan la validez transnacional de los factores sociales que determinan las disposiciones sociopsicológicas de hijos de inmigrantes. Desde un punto de vista práctico, el proceso por el cual estos adolescentes se hacen mayores en España parece «normal», tanto desde el punto de vista de sus promedios como de sus determinantes causales. En comparación con lo hallado en Estados Unidos, la principal diferencia está en la alta proporción de los que pretenderían vivir en el extranjero cuando se conviertan en adultos. Sin embargo, tal y como apuntó el director de una de las escuelas de Madrid incluidas en la encuesta: «No hay nada excepcional en esto, los niños españoles también sueñan con vivir en América o en el norte de Europa, incluso el mío». Esta afirmación sugiere que la «anomalía» detectada en nuestros datos no es tal, sino que refleja las condiciones generales de la España actual y una valoración realista de las oportunidades por ella ofrecidas. Tal valoración parecería ser común a muchos jóvenes españoles, y no solo a los de segunda generación.

\section{Referencias bibliográficas}

Altschul, Inna; Oyserman, Daphna y Bybee, Deborah (2008). «Racial-Ethnic Self-Schemas and Segmented Assimilation: Identity and the Academic Achievement of Hispanic Youth». Social Psychology Quarterly, 71, 302-320.

ANDALL, J. (2002). «Second-generation attitude?: African-Italians in Milan». Journal of Ethnic and Migration Studies, 28, 389-407.

APARICIO, Rosa (2006). Hijos de inmigrantes que se hacen adultos. Madrid: Observatorio Permanente de la Inmigración. Ministerio de Trabajo e Inmigración.

APARICIO, Rosa y TORNOS, Andrés (2008). «Aproximación al Estudio de las Bandas Latinas en Madrid». Madrid: Ministerio de Trabajo e Inmigración.

ARriagadA, P. A. (2007). "In search of an identity in young adulthood: Ethnic self-identification among children of immigrants». Ohio State University. 
BAILEY, Benjamin (2000). "Language and Negotiation of Ethnic/Racial Identity Among Dominican Americans». Language in Society, 29, 555-582.

- (2001). «Dominican-American Ethnic/Racial Identities and United States Social Categories». International Migration Review, 35, 677-708.

CACHÓn, Lorenzo (2009). La España immigrante. Barcelona: Anthropos.

CalavitA, Kitty (2005). Immigrants at the Margins: Law, Race, and Exclusion in Southern Europe. Cambridge, UK: Cambridge University Press.

Carvajal Gómez, María Isabel (2006). «Evolución de las cifras de extranjeros con tarjeta de autorización en vigor». En: AJA, E. y ArangO, J. (ed.). Veinte años de inmigración en España: Perspectivas juridicas. Barcelona: Fundación CIDOB, 85-112.

DiEHL, Claudia y SCHNELL, Rainer (2006). "Reactive Ethnicity" or "Assimilation"?: Statements, Arguments, and First Empirical Evidence for Labor Migrants in Germany». International Migration Review, 40, 786-816.

Díez Nicolás, Juan (2006). Las dos caras de la inmigración. Madrid: Observatorio Permanente de la Inmigración. Ministerio de Trabajo e Inmigración.

Duncan, Brian y Trejo, Stephen J. (n. d.). «Ancestry Versus Ethnicity: The Complexity and Selectivity of Mexican Identification in the United States». SSRN eLibrary [en línea]. <http://papers.ssrn.com/sol3/papers.cfm?abstract_id=1150721> [Consulta: 15 octubre 2009]

FArVer, Jo Ann M.; NARANG, Sonia K. y BhadHA, Bakhtawar R. (2002). «East meets West: Ethnic identity, acculturation, and conflict in Asian Indian families». Journal of Family Psychology, 16, 338-350.

FeliCiAnO, Cynthia (2009). «Education and Ethnic Identity Formation among Children of Latin American and Caribbean Immigrants». Sociological Perspectives, 52, $135-158$.

Feliciano, Cynthia y Rumbaut, Rubén (2005). "Gendered Paths: Educational and Occupational Expectations and Outcomes Among Adult Children of Immigrants». Ethnic and Racial Studies, 28 (noviembre), 1087-1118.

Firebaugh, Glenn (2008). Seven Rules for Social Research. Princeton, NJ: Princeton University Press.

Fishman, Joshua A. (1981). «Language Maintenance». En: Thernstrom, Stephan (ed.). Harvard Encyclopedia of American Ethnic Groups. Cambridge, MA: Harvard University Press, 629-38.

Glazer, Nathan (1954). "Ethnic Groups in America». En: Berger, T. A. M. y PAGE, C. Freedom and Control in Modern Society. Nueva York: Van Nostrand, 158-73.

Golash-BozA, Tanya (2006). «Dropping the Hyphen? Becoming Latino(a)-American through Racialized Assimilation». Social Forces, 85, 27-55.

Grascia, Andrew M. (2004). «Gang Violence: Mara Salvatrucha - Forever Salvador». Journal of Gang Research, 11 (2), 29-36.

GUALDA, Estrella (2009). «Aspiraciones y expectativas educativas y laborales de jóvenes inmigrantes e hijos de inmigrantes escolarizados». Comunicación presentada en el VI Congreso de Migración en España, La Coruña (septiembre).

HaKuTA, Kenji (1986). Mirror of Language: The Debate on Bilingualism. Nueva York: Basic Books.

HugHeS, Diane et al. (2006). «Parents' ethnic-racial socialization practices: A review of research and directions for future study». Developmental Psychology, 42, 747-770.

JiméneZ, Tomás R. (2008). «Mexican Immigrant Replenishment and the Continuing Significance of Ethnicity and Race». American Journal of Sociology, 113, 1527-1567. 
Keaton, Trica Danielle (2006). Muslim Girls and the other France: Race, Identity Politics and Social Exclusion. Bloomington: Indiana University Press.

KisH, Leslie (1967). Survey Sampling. Nueva York: Wiley.

Lieberson, Stanley (1980). A Piece of the Pie, Blacks and White Immigrants Since 1880. Berkeley: University of California Press.

LOPEZ, David E. (1982). Language Maintenance and Shift in the United States Today: The Basic Patterns and Their Social Implications. Vol. 1-4. Los Alamitos, CA: National Center for Bilingual Research.

Louie, Vivian (2006). "Growing up Ethnic in Transnational Worlds: Identities Among Second-Generation Chinese and Dominicans». Identities: Global Studies in Power and Culture, 13, 363-394.

MaCIAS, Thomas (2004). «Imaginándose Mexicano: The Symbolic Context of Mexican American Ethnicity Beyond the Second Generation». Qualitative Sociology, 27, 299-315.

MaruYAma, Geoffrey (1998). Basics of Structural Equation Modeling. Thousand Oaks, CA: Sage.

ObSERVATORIO PERMANENTE de la INMIGRACIÓN (2009). Boletín Estadístico de Extranjería e Inmigración a España \#19 [en línea]. Madrid: Ministerio de Trabajo e Inmigración <http://extranjeros.mtin.es>.

Ono, Hiromi (2002). «Assimilation, Ethnic Competition, and Ethnic Identities of U.S.-Born Persons of Mexican Origin». International Migration Review, 36, 726745.

Pajares, Miguel (2009). «La immigración en España: Sus causas y las politicas con las que se gestiona». En: Checa Olmos, F.; Checa, C. y Arjona A. (ed.). Las migraciones en el mundo. Barcelona: Icaria Antrazyt, 175-192.

Perlmann, Joel (2005). Italians Then, Mexicans Now: Immigrant Origins and Second Generation Progress 1980-2000. Nueva York: Russell Sage Foundation y Levy Institute.

PORTES, Alejandro y HaO, Lingxin (1998). «E Pluribus Unum: Bilingualism and loss of language in the second generation». Sociology of Education, 71 (4), 269-294.

PORTES, Alejandro y MACLEOD, Dag (1996). "What shall I call myself? Hispanic identity formation in the second generation». Ethnic \& Racial Studies, 19, 523-547.

PORTES, Alejandro y Rumbaut, Ruben G. (2001). Legacies: The Story of the Immigrant Second Generation. Berkeley, CA: University of California Press and Russell Sage Foundation.

PorTes, Alejandro y ZHOU, Min (1992). "Gaining the Upper Hand: Economic Mobility Among Immigrant and Domestic Minorities». Ethnic and Racial Studies, $15,491-522$.

Rosenberg, Morris (1965). Society and Adolescent Self-Image. Princeton, NJ: Princeton University Press.

Rumbaut, Rubén G. (1996). «Origins and Destinies: Immigration, Race and Ethnicity in Contemporary America». En: Pedraza, Silvia y Rumbaut, Ruben (eds.). Origins and Destinies. Belmont, California: Wadsworth Publishing Co.

- (2004). «Ages, Life Stages, and Generational Cohorts: Decomposing the Immigrant First and Second Generations in the United States». International Migration Review, 38 (otoño), 1160-1205.

- (2005). "Turning Points in the Transition to Adulthood: Determinants of Educational Attainment, Incarceration, and Early Childbearing among Children of Immigrants». Ethnic and Racial Studies, 28 (noviembre), 1041-1086. 
Rumbaut, Rubén G. y PORTES, Alejandro (2001). Ethnicities: Children of Immigrants in America. Berkeley: University of California Press and Russell Sage Foundation.

SAN JuAN, Karin Aguilar (2005). "Staying Vietnamese: Community and Place in Orange County and Boston». City and Community, 4, 37-65.

Schneider, Cathy L. (2008). «Police Power and Race Riots in Paris». Politics and Society, 36 (1), 133-159.

SOTELO, Ignacio (2005). «La gran contradicción europea». El País, 30 de octubre, 15.

VAN NieKERK, Mies (2007). «Second-Generation Caribbeans in the Netherlands: Different Migration Histories, Diverging Trajectories». Journal of Ethnic and Migration Studies, 33, 1063-1081.

VIGIL, Jaime D. (2002). A Rainbow of Gangs: Street Cultures in the Mega-City. Austin, TX: University of Texas Press.

Waters, Mary (1996). "West Indian Family Resources and Adolescent Outcomes». Ponencia presentada en el Encuentro de la American Association for the Advancement of Science. Baltimore, febrero.

ZarATe, Maria Estela; Bhimji, Fazila y ReEse, Leslie (2005). «Ethnic Identity and Academic Achievement Among Latino/a Adolescents». Journal of Latinos \& Education, 4, 95-114.

Zhou, Min y Bankston III, Carl N. (1996). "Social Capital and the Adaptation of the Second Generation: The Case of Vietnamese Youth in New Orleans». En: Portes, A. (ed.). The New Second Generation. Nueva York: Russell Sage, 197-220.

Zhou, Min; Lee, Jennifer; Vallejo, Jody A.; Tafoga-Estrada, Rosaura y SoA XIONG, Yang (2008). «Success Attained, Deterred, and Denied: Divergent Pathways to Social Mobility in Los Angeles' New Second Generation». Annals of the American Academy of Political and Social Sciences, 620 (noviembre), 37-61. 


\section{Apéndice. Estadísticas descriptivas para variables utilizadas en el análisis}

\begin{tabular}{|c|c|c|c|}
\hline Variable & Nivel de medida & Códigos de rango o valor & Media o proporción \\
\hline \multicolumn{4}{|l|}{ Resultados } \\
\hline Autoidentificación como españoles & Dicotómico & $\begin{array}{l}1=\text { Sí } \\
0=\text { No }\end{array}$ & 0,30 \\
\hline País de residencia deseado & Dicotómico & $\begin{array}{l}1=\text { España } \\
0=0 \text { tros }\end{array}$ & 0,26 \\
\hline Actitud hacia España & Ordinal & $\begin{array}{l}2=\text { Positivo } \\
1=\text { Neutro } \\
0=\text { Negativo }\end{array}$ & 0,51 \\
\hline Autoestima & Intervalo & $1-4$ & 2,97 \\
\hline \multicolumn{4}{|l|}{ Predictores } \\
\hline Edad & Intervalo & $12-19$ & 13,91 \\
\hline Sexo & Dicotómico & $\begin{array}{l}1=\text { Mujer } \\
0=\text { Hombre }\end{array}$ & 0,49 \\
\hline Ciudad de residencia & Dicotómico & $\begin{array}{l}1=\text { Barcelona } \\
0=\text { Madrid }\end{array}$ & 0,52 \\
\hline Lugar de nacimiento & Dicotómico & $\begin{array}{l}1=\text { España } \\
0=\text { Extranjero }\end{array}$ & 0,15 \\
\hline Periodo de residencia en España & Intervalo & $0-17$ & 5,39 \\
\hline Estatus scioeconómico familiar & Intervalo & $-1,58-4,46$ & $-0,01$ \\
\hline Índice conocimiento español & Intervalo & $1-4$ & 3,55 \\
\hline Relaciones intergeneracionales & Intervalo & $1-3,75$ & 2,88 \\
\hline Lugar de nacimiento del padre & Dicotómico & $\begin{array}{l}1=\text { España } \\
0=\text { Extranjero }\end{array}$ & 0,05 \\
\hline Lugar de nacimiento de la madre & Dicotómico & $\begin{array}{l}1=\text { España } \\
0=\text { Extranjero }\end{array}$ & 0,04 \\
\hline Experiencias de discriminación & Dicotómico & $\begin{array}{l}1=\text { muchas } / \text { alguna } \\
0=\text { ninguna }\end{array}$ & 0,49 \\
\hline Un padre nacido en España & Dicotómico & $\begin{array}{l}1=\mathrm{Si} \\
0=\mathrm{No}\end{array}$ & 0,09 \\
\hline \multicolumn{4}{|l|}{ Orígenes nacionales } \\
\hline Argentina & Dicotómico & $\begin{array}{l}1=\mathrm{Si} \\
0=\mathrm{No}\end{array}$ & 0,03 \\
\hline Bolivia & Dicotómico & $\begin{array}{l}1=\mathrm{Si} \\
0=\mathrm{No}\end{array}$ & 0,05 \\
\hline Andino o caribeño & Dicotómico & $\begin{array}{l}1=\mathrm{Si} \\
0=\mathrm{N} 0\end{array}$ & 0,52 \\
\hline China & Dicotómico & $\begin{array}{l}1=\mathrm{Si} \\
0=\mathrm{No}\end{array}$ & 0,04 \\
\hline Colombia & Dicotómico & $\begin{array}{l}1=\mathrm{Si} \\
0=\mathrm{No}\end{array}$ & 0,08 \\
\hline República Dominicana & Dicotómico & $\begin{array}{l}1=\mathrm{Si} \\
0=\mathrm{No}\end{array}$ & 0,06 \\
\hline Ecuador & Dicotómico & $\begin{array}{l}1=\mathrm{Si} \\
0=\mathrm{No}\end{array}$ & 0,27 \\
\hline Marruecos & Dicotómico & $\begin{array}{l}1=\mathrm{Si} \\
0=\mathrm{No}\end{array}$ & 0,10 \\
\hline Otros Europa occidental & Dicotómico & $\begin{array}{l}1=\mathrm{Si} \\
0=\mathrm{No}\end{array}$ & 0,04 \\
\hline Pakistán & Dicotómico & $\begin{array}{l}1=\mathrm{Si} \\
0=\mathrm{No}\end{array}$ & 0,02 \\
\hline Perú & Dicotómico & $\begin{array}{l}1=\mathrm{Si} \\
0=\mathrm{No}\end{array}$ & 0,06 \\
\hline Filipinas & Dicotómico & $\begin{array}{l}1=\mathrm{Si} \\
0=\mathrm{No}\end{array}$ & 0,03 \\
\hline Rumanía & Dicotómico & $\begin{array}{l}1=\mathrm{Si} \\
0=\mathrm{No}\end{array}$ & 0,05 \\
\hline
\end{tabular}

Fuente: Estudio Longitudinal de la Segunda Generación (ILSEG). 


$\begin{array}{ll}- & 0 \\ - & 0 \\ - & 0\end{array}$

0

0

0

1

0

0

1

0,44

1,22

2,95

$\begin{array}{ll}- & - \\ - & - \\ 0 & -\end{array}$

$-$

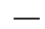

0

0

1

-

0

0

0

3,80

0,74

0,60

5,00

$-0,10$

0,56

3,75

300

-

0

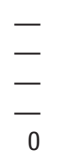

-

$\frac{-}{\bar{z}}$

$\overline{-}$



0

0

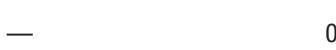

$-$

0

1

$-0$

0

0

-

0

0

0

0

-

0

-

1

1

-

0

- 0

0

-

0

-

1

-

0

- 0

0

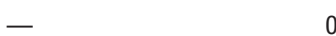

0

0

0

0

- 